\title{
Heavy-Duty Diesel Engine Spray Combustion Processes: Experiments and Numerical Simulations
}

Noud Maes, Nico Dam, and Bart Somers Eindhoven University of Technology

Tommaso Lucchini and Gianluca D'Errico Politecnico di Milano

Gilles Hardy FPT Motorenforschung AG

Citation: Maes, N., Dam, N., Somers, B., Lucchini, T. et al., "Heavy-Duty Diesel Engine Spray Combustion Processes: Experiments and Numerical Simulations," SAE Technical Paper 2018-01-1689, 2018, doi:10.4271/2018-01-1689.

\section{Abstract}

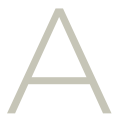

contemporary approach for improving and developing the understanding of heavy-duty Diesel engine combustion processes is to use a concerted effort between experiments at well-characterized boundary conditions and detailed, high-fidelity models. In this paper, combustion processes of $n$-dodecane fuel sprays under heavy-duty Diesel engine conditions are investigated using this approach. Reacting fuel sprays are studied in a constant-volume pre-burn vessel at an ambient temperature of $900 \mathrm{~K}$ with three reference cases having specific combinations of injection pressure, ambient density and ambient oxygen concentration (80, 150 $\& 160 \mathrm{MPa}-22.8 \& 40 \mathrm{~kg} / \mathrm{m}^{3}-15 \& 20.5 \% \mathrm{O}_{2}$ ). In addition to a free jet, two different walls were placed inside the combustion vessel to study flame-wall interaction. Experimentally, low- and high-temperature reaction product distributions are imaged simultaneously using single-shot planar laser-induced fluorescence (PLIF) of formaldehyde and high-speed line-ofsight imaging of the chemically-excited hydroxyl radical $\left(\mathrm{OH}^{*}\right)$. Interference of soot incandescence in experimental $\mathrm{OH}^{*}$ recordings is assessed to improve interpretation of the results. Interference by poly-cyclic aromatic hydrocarbon (PAH) LIF and soot radiation is mostly evaded by evaluating flame structures shortly after ignition for one of the studied cases, but presumably included in others. Simulations were performed using a recently developed computational fluid dynamics (CFD) methodology with detailed chemistry and turbulence-chemistry interaction. Apart from the capability to model flame structures and combustion indicators based on optical diagnostics, heat-release rate trends are predicted accurately at varying boundary conditions. Significant variation in the distribution of low-temperature combustion products under heavy-duty operating conditions are explained using both CFD simulations and a one-dimensional jet model.

\section{Introduction}

espite unequivocal improvements in alternative energy sources for transportation purposes, propulsion that is assisted or fully powered by liquid fuels is expected to remain dominant for the foreseeable future. Especially for long-haul transport applications and propulsion requirements at relatively remote locations, heavy-duty Diesel engines provide the primary solution. Certainly, these engines will profit from, and will be required to achieve, a reduction in fuel consumption and harmful emissions, illustrating the need for detailed understanding of the in-cylinder processes. Studies that combine experimental and numerical approaches have been shown to provide additional insights into such processes $[\underline{1}, \underline{2}, \underline{3}, \underline{4}, \underline{5}]$. Data that is either difficult or impossible to probe by experiments can often be obtained from simulations, which may expose underlying mechanisms after validation of the numerical models using reliable experimental reference from attainable markers. Such revelations hold potential to push, or even break the typical trade-offs known from direct-injected Diesel engines [] $]$.
Concerning the predictability of models, one can break down the system into the multi-phase flow mixing process and combustion, with sub-models taking into account different time and length scales. Validating correct simulation of these separate components individually, however, does not necessarily account for all processes relevant to a high-pressure spray flame. When neglecting, or improperly incorporating interactions between flow and chemistry, important combustion parameters are most likely to be predicted poorly $[\underline{2}, \underline{7}, \underline{8}]$. Examples of such combustion parameters are the time it takes for the fuel to ignite, called the ignition delay (ID) and the flame lift-off length (FLOL), which is the distance from the injector where the flame stabilizes. Many approaches for simulating high-pressure spray flames are being developed simultaneously at the moment, using different numerical frameworks and different methods of incorporating the interactions between the flow and chemistry $[\underline{2}, \underline{9}, \underline{10}, \underline{11}, \underline{12}]$. A large part of these contributions is focused on validation within the engine combustion network (ECN), a consortium with orchestrated target conditions using nominally similar injection equipment [13]. 
To accurately understand the behavior of reacting fuel sprays in a heavy-duty environment, one would ideally stay close to the system of interest in terms of operating conditions and heat transfer. In that case, however, analysis of the pressure-history and exhaust gas composition are generally the only reference for numerical simulations, giving no insight into the spatial flame distribution. Using an optical engine, operating conditions can be roughly matched to a metal single-cylinder, although typically at low-load and low-speed while requiring corrections for the increased crevices and extended optical piston [14]. The advantages of constantvolume vessels are principally found in the improved optical access without moving parts that may interfere with the spray, and an increased operating range [15]. Furthermore, uncertainties in boundary conditions are reduced by the ability to accurately determine the ambient pressure and core temperature $[\underline{16}, \underline{17}, \underline{18}]$. For accurate modeling comparison, such accuracy is key to fine-tune referenced conditions and to predict trends reliably.

A missing link in the transit from simulations of sprays in a quiescent chamber to a full metal engine, apart from including more complicated flow patterns, and moving and adaptive mesh configurations, is the interaction between the spray flame and the piston-bowl. Flame-wall interaction is inevitable in most heavy-duty applications, and poses an interesting target for optimization. Although relevant to many enclosed systems, few studies involve wall interaction, potentially due to the added complexity for both experiments and numerical simulations [19]. Reflections, beam-steering, additional variables and components, and reduced optical access may impede experimental data collection and interpretation. From a numerical standpoint, challenges include insufficient availability of validation data, unknown boundary layer characteristics and a lack of knowledge on the applicability of existing combustion models in the near-wall region [19]. Wall interaction studies with inert sprays at conditions relevant to compression ignition engines have revealed that while there is no observable influence on the spray before impingement, mixing may be significantly influenced in the contact region $[20,21,22,23]$. Specifically, Bruneaux showed how the center impingement region near the spray axis, where the jet first impinges on the wall, mixing is reduced compared to a free jet [21]. Moving radially outward along the wall to the region where the spray moves perpendicular to the spray axis, mixing is increased again. When wall distance and injection conditions are selected such that the wall jet region that surrounds the impingement region is dominant, the spray will exhibit an overall mixing improvement compared to a free jet, while differences in air entrainment were found insignificant.

The consequence of simplified jet-wall interaction on combustion has been studied by several research groups as well over the past decade $[\underline{24}, \underline{25}, \underline{26}, \underline{27}]$. Variations in spray, ambient conditions and wall properties, which lead to differences in mixing as described above, are likely causes of ambiguities in terms of soot production as discussed in some of these flame-wall interaction studies. In the study by Pickett et al., the potential to diminish or even eliminate soot formation using flame-wall interaction when compared to a free jet is shown for two different injector orifices, and two wall distances [24]. In addition, they showed how a rectangular box, or so-called "confined" configuration, results in a decreased lift-off length due to the redirected combustion gases. The main goal of this confined configuration was the simulation of jet-jet interaction between adjacent sprays in an internal combustion engine. The consequence of a shortening lift-off with similar mixing subsequently led to more soot formation, following the outcomes of previous soot studies [28]. On the other hand, the study by Wang et al., reports on increased soot formation when a wall insert is placed at a relatively short distance from the injector [27]. This indicates an influence by the aforementioned ambient conditions and properties, although a conclusive understanding might still be missing due to insufficient research with respect to this specific subject [19].

Similar to a previous comparison [4], an attempt is made in this work to keep a close coupling between experiments and simulations, and to study cases with densities ranging up to $40 \mathrm{~kg} / \mathrm{m}^{3}$ to be relevant to contemporary heavy-duty Diesel engine operation. The goal of the previous study was the development of a better understanding and a new approach to model inert sprays at the conditions of interest. This work continues by including combustion under these circumstances. Ignition and combustion are studied experimentally by PLIF, $\mathrm{OH}^{*}$ chemiluminescence and pressure analysis. The use of $\mathrm{OH}^{*}$ chemiluminescence at $310 \mathrm{~nm}$ is a traditional and well-established approach for defining the lift-off length, giving the best detectability and image quality of the most upstream flame location [29]. However, the fact that soot incandescence contributes to the downstream region is sometimes overlooked $[\underline{29}, \underline{30}, \underline{31}]$. Comparisons between experimental and numerical $\mathrm{OH}^{*}$ fields can potentially benefit from estimation or illustration of the effect of soot incandescence in the downstream region of the spray. To aid in the interpretation and understanding of observed trends in low-temperature combustion products, the one-dimensional jet model by Musculus and Katke is used to predict local equivalence ratios [32]. Modeling both characteristic flame structures and properties with the capability to match heat release rates lays the foundation to expand the simulations to full metal engines. To improve both understanding of flame-wall interaction, and to develop models which are capable of predicting processes that occur near an impingement surface, two different wall inserts were designed for this study. The first design is a simplified, flat wall which can easily be compared to the design that other researchers have used $[\underline{24}, \underline{25}, \underline{26}, \underline{27}]$. For the second design, a smooth $2 \mathrm{D}$ confined shape is used to simulate the piston bowl- rim. The confined design is developed such that it isolates the influence caused by the wall shape, opposed to the jet-jet interaction as studied by Pickett et al. [24]

\section{Methods and Approach}

A combination of experimental and numerical work was implemented to study the reacting fuel sprays at heavy-duty Diesel engine conditions. The following sections will discuss the experimental setup with applied optical diagnostic techniques and pressure analysis, followed by the numerical setup to simulate the spray- and combustion processes. Similar to 
previous studies, due attention is paid to the method of comparison between experiments and simulations to ensure proper validation and to identify similarities and anomalies $[\underline{4}, \underline{12}]$.

\section{Experimental}

Pre-Burn Combustion Vessel and Injection Equipment In this work, a constant-volume pre-burn vessel was used to achieve pre-computed target conditions at pressures and temperatures that are representative of top dead center in a heavy-duty Diesel engine. The pre-burn charge consists of a configurable mixture of acetylene, nitrogen, oxygen and argon and is ignited using commercial automotive spark plugs. After the pre-burn, the ambient inside the vessel contains 6.4 vol- $\% \mathrm{CO}_{2}$, and 3.2 vol- $\% \mathrm{H}_{2} \mathrm{O}$. The volume of the cubical combustion chamber is about $1260 \mathrm{cc}$, and a Bosch solenoid-activated $0.205-\mathrm{mm}$ single orifice common-rail injector with a k-factor of 1.5 is installed in one of the side ports. In addition to tapering, the nozzle is subjected to hydroerosive grinding to suppress cavitation as far as possible [33]. Pure $\mathrm{n}$-dodecane is pressurized using a double acting airdriven fuel pump and monitored at the fuel line to the injector using a fuel pressure sensor. See Table 1 for information on the auxiliary equipment. All other ports of the combustion vessel can be made optically accessible using either fused silica or sapphire windows, but only the latter were used for the high-density cases in this study. When optical access is not required, metal blanks can be installed. An rpm-controlled mixing fan is fitted to one of the diagonal ports and operates throughout the experiment at $2000 \mathrm{rpm}$ to homogenize the pre-combustion mixture and temperature distribution before injection. Intake and exhaust ports, a burst disk and a vesselpressure transducer are installed in the remaining diagonals.

Wall Configurations Two different stainless-steel wall designs were studied in this work. A simplified flat wall configuration, and a smooth $2 \mathrm{D}$ confined shape that simulates the geometry of a piston bowl-rim which divides the spray into the bowl and the squish region, see the expanded view in Figure 1. The circle-arc of a true piston segment, however, is neglected such that it does not obstruct optical access, and the division between bowl and squish region is symmetrical. The flat plane wall is circular and has a diameter of $50 \mathrm{~mm}$, while the confined wall is $50 \times 50 \times 21 \mathrm{~mm}$ with the same volume to prevent ambiguities in the filling procedure and

TABLE 1 Details of auxiliary equipment used for the combustion vessel.

\begin{tabular}{|c|c|}
\hline Fuel pump & Resato P16-400-2 \\
\hline Fuel injector & Bosch CRI2 solenoid $(0.205 \mathrm{~mm})$ \\
\hline Injector driver & EFS IPoD 8532 \\
\hline Fuel pressure sensor & Kistler 4067E3000 \\
\hline Vessel pressure sensor & Kistler 6041 AU20 \\
\hline Burst disk rupture pressure & $35 \mathrm{MPa}$ \\
\hline Vessel volume & $1260 \mathrm{cc}$ \\
\hline Mixing fan motor & Maxon motor (custom) \\
\hline Inlet and exhaust valves & Sitec 710.3124-D \\
\hline
\end{tabular}

FIGURE 1 Schematic overview of the constant volume combustion vessel with simultaneous high-speed $\mathrm{OH}^{*}$ chemiluminescence and formaldehyde PLIF detection. The laser sheet passes through the vessel from the top, and intersects the spray axis before exiting the vessel in the bottom. The expanded view shows the shape and location of the confined wall design inside the vessel.

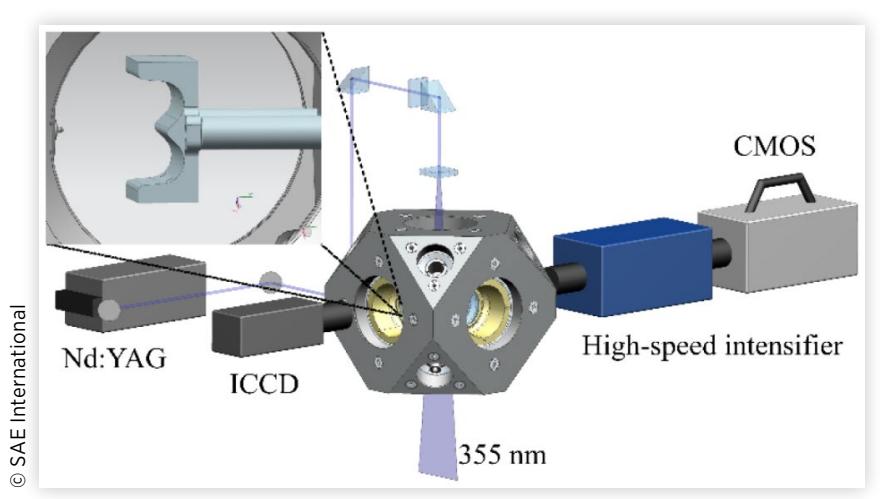

cool down behavior between the two cases. The walls were mounted on two support posts and attached to the metal window blank opposite from the injector. The length of the posts can be varied in future studies to change the distance between the injector and the wall, again while maintaining the same volume.

Gas temperature measurements were carried out using $50-\mu \mathrm{m}$ type- $\mathrm{R}$ thermocouples with a time-constant of about $3 \mathrm{~ms}$, to characterize the ratio between the core temperature and the pressure-deduced bulk temperature [17, 18]. No significant influence on the temperature ratio was detected in effect of the decrease of volume and the added wall insert. However, a reduced peak temperature due to the heat exchange with the wall and therefore a decreased cool-down time were noticed for the pre-combustion.

Liquid impingement was obviated by placing the centerline of the wall inserts at a distance of $52.2 \mathrm{~mm}$ from the injector orifice to simulate a typical heavy-duty Diesel engine geometry. Owing to the design of the confined wall, the spray is allowed to travel slightly beyond this $52.2 \mathrm{~mm}$ in the direction parallel to the spray axis, after which the curvature forces it backwards. Different sized sheathed Type-K thermocouples $(0.5$ and $0.25 \mathrm{~mm})$ were installed flush with the insert surface at several locations, and provided wall temperatures during the experiments. The time constants are $0.28 \mathrm{~s}$ and $0.8 \mathrm{~s}$ for the $0.25-\mathrm{mm}$ and the $0.5-\mathrm{mm}$ thermocouples, respectively. Unfortunately, the lifetime of the $0.25-\mathrm{mm}$ thermocouple wires on the rear side of the inserts was limited because of the exposure to the high-temperature pre-combustion, in excess of $1700 \mathrm{~K}$. However, they did give a reading of the approximate wall temperature in the limited number of tests that where performed. For further tests, only the $0.5-\mathrm{mm}$ thermocouples could be used. Although the $0.5-\mathrm{mm}$ thermocouples were not sensitive enough to extract meaningful information during the impingement because of the relatively large time constant, they too provided an approximate reading of the wall temperature before the start of injection. At the start of injection, the $0.25-\mathrm{mm}$ thermocouples showed a decreasing temperature 
trend, approaching $500 \mathrm{~K}$, while the $0.5-\mathrm{mm}$ thermocouples showed minimal temperature changes around $500 \mathrm{~K}$. Based on these results, the wall temperature is estimated at $500 \mathrm{~K}$ (+/-25 K).

Optical Arrangement Chemiluminescence imaging and PLIF were applied simultaneously to compare the distributions originating from first- and second-stage ignition phenomena. The cameras were placed opposite to each other to get a similar perspective. However, the chemiluminescence is the net result of all the light along the line-of-sight, whereas the fluorescence only originates from the laser-illuminated plane. A schematic overview of the setup is shown in Figure 1. For each boundary condition, the experimental results presented here consist of ensemble-averaged images based on 10 to 15 individual experiments, which is typical for studies in constant volume vessels [34]. Results obtained using a spectrograph and a smaller orifice injector, however, are based on single-shot results.

Formaldehyde PLIF Imaging First stage ignition products were visualized by formaldehyde PLIF using the third harmonic of a $10 \mathrm{~Hz}$ Nd:YAG laser (Spectra-Physics Quanta-Ray PRO-250) at $355 \mathrm{~nm}$ for excitation. The laser light sheet of approximately $70 \times 0.5 \mathrm{~mm}$ was formed using two cylindrical lenses and had a typical energy of $90 \mathrm{~mJ} /$ pulse before entering the combustion vessel from the top. Fluorescence was recorded during a 100-ns gate time using an ICCD camera (PI-MAX 3, Unigen II photocathode) with a 50-mm objective (Nikkor AF-D f/1.4) and a band-pass filter centered around $380 \mathrm{~nm}$ (Semrock, $46 \mathrm{~nm}$ FWHM). By limiting the collection to the part of the spectrum below $440 \mathrm{~nm}$, an attempt was made to limit the interference by poly-cyclic aromatic hydrocarbon $(\mathrm{PAH})$ fluorescence and soot radiation excited by the same wavelength [35, 36]. The experiments shown here were also performed shortly after auto-ignition of the fuel, before soot is formed. This approach was proven useful due to the rapid stabilization of the $\mathrm{CH}_{2} \mathrm{O}$ distribution in previous studies, which is subsequently joined by a more intense structure of PAH fluorescence as the sooting propensity increases $[\underline{34}, \underline{35}, \underline{37}]$. However, in the current study we also show strong evidence that due to the large orifice and higher reactivity of the ambient conditions, $\mathrm{PAH}$ are likely to be found at similar axial distances from the injector in downstream regions, hindering interpretation due to a lack of clear spatial separation.

$\mathrm{OH}^{*}$ Chemiluminescence Imaging For the second stage ignition products, high-speed $\mathrm{OH}^{*}$ chemiluminescence was recorded at $40 \mathrm{kHz}$ with a $10 \mu$ s gate time, using a CMOS camera (Photron SA-Z) lens-coupled to a high-speed intensifier (LaVision, S20 photocathode). Light was collected by a 100-mm UV objective (Bernhard Halle Nachfl., f/2) and a filter pack consisting of a narrow-band filter centered near the $\mathrm{OH}^{*}$ emission at $315 \mathrm{~nm}$ (Semrock, $20 \mathrm{~nm}$ FWHM) and a second band-pass centered at 300-nm (Semrock, $88 \mathrm{~nm}$ FWHM) to suppress soot incandescence. Intensifier settings were adjusted between different operating conditions to utilize the dynamic range of the camera while preventing overexposure. To help interpret the images obtained by the high-speed
$\mathrm{OH}^{*}$ imaging system, two additional approaches were used for select cases. As a first approach, the 315-nm filter was replaced by a filter centered at $340 \mathrm{~nm}$ (Semrock, $26 \mathrm{~nm}$ FWHM) to have similar transmission when compared to the dedicated chemiluminescence filter set, while evading the $\mathrm{OH}^{*}$ emission peak. This filter set will be referred to as the "soot filters" in this work, and intensifier settings were kept similar to the $\mathrm{OH}^{*}$ filter pack when comparing at a single boundary condition. As a second approach in separate experiments with a different injector (but similar boundary conditions), an ICCD camera (PI-MAX 1, SB slow intensifier) was coupled to a spectrograph with the slit parallel to the spray axis. The spectrograph was equipped with a $64-\mathrm{mm}$ UV objective (Bernhard Halla Nachfl., f/2) and the slit was aligned approximately $2 \mathrm{~mm}$ above the spray axis to coincide with the brightest region at the flame-lift off for the given condition. Using the spectrograph, chemiluminescence and incandescence signal were decomposed by the grating and imaged as a function of axial distance.

Pressure Analysis Pressure in the combustion vessel was measured at a rate of $50 \mathrm{kHz}$ using a piezoelectric pressure transducer (Kistler 6045A) placed in one of the diagonals opposite from the injector. The obtained pressure signal is corrected for the pressure decay before and after the fuel injection, as well as the local speed-of-sound in the vessel based on the location of the flame lift-off length, similar to ref. [ㅌ6]. A low-order filtering procedure is used to smooth the pressure signal, prior to calculating the apparent heat release rate (AHRR) according to Heywood [38]. Additional filtering of the AHRR is applied after ignition, reducing the periodic pressure oscillations originating from the initial pre-mixed, auto-igniting fuel. A pressure based ignition delay is determined based on a 50 -mbar increase of the vessel pressure after the corrections, which is slightly higher compared to a previous study [6ㅡ. Here, injection rates and the amount of injected mass are significantly higher due to the large orifice injector and long injection durations. Therefore, the pressure rise at ignition is relatively strong, allowing a slightly higher threshold.

\section{Numerical}

Computational fluid dynamics (CFD) simulations were carried out using the Lib-ICE code, a set of libraries and solvers for IC Engine simulations developed under the OpenFOAM $^{\circledR}$ technology, which was extensively used and validated with Diesel sprays in constant-volume chamber and engine experiments under both non-reacting and reacting conditions $[\underline{4}, \underline{12}, \underline{39}]$.

Spray Model The spray is modeled with the Lagrangian approach, where pockets of droplets with the same properties (parcels) are tracked in the CFD domain according to the mass, momentum and energy exchange with the continuous gas phase, which is treated in an Eulerian way. To correctly describe the spray evolution, sub-models are required to predict the jet atomization, secondary breakup, evaporation, collision, heat transfer and turbulent dispersion. In a previous 
study [4], the proposed methodology for spray simulations was extensively validated at non-reacting conditions considering ambient density and temperature values like those encountered in this work. The Huh-Gosman model was used for jet atomization, which takes into account turbulent and aerodynamic instabilities [누]. The size of the secondary droplets stripped from the liquid jet is sampled from a probability density function distribution that depends on the turbulent length scale at a certain breakup time. Secondary droplets are supposed to be limited to wave breakup with a rate and stable droplet size as function of the Weber number.

Combustion Model Diesel combustion is affected by the complex interplay between turbulence and chemistry which determines the auto-ignition time, heat release rate during mixing controlled combustion and the distance from the nozzle at which the flame stabilizes (lift-off length) [ㄴ1, $\underline{42}]$. Different approaches to couple turbulence and chemistry were proposed in the past and they can be mainly classified in the way chemical kinetics and turbulence-chemistry interaction are handled. Considering the chemistry, it is important to notice that the two possible solutions are either the use of direct integration, or to generate an offline look-up table. The first approach is computationally very demanding due to the necessity of employing stiff solvers with very small time-steps and very small cell sizes to capture the local flame structure, essentially rendering it a direct numerical simulation (DNS). This aspect introduces several limitations for the maximum number of species that can be used in practical simulations and the consequent accuracy of the adopted mechanism. If the subgrid structure is assumed (e.g. perfectly stirred reactor or laminar diffusion flame) the cell size restriction can be lifted at the expense of extra overhead to describe the sub-grid mixing and turbulence chemistry interaction. This is related to the integration of the presumed probability function, or the transport of many species and energy equations such as the number of simulated flow realizations or stochastic fields [43]. Therefore, tabulated kinetics can offer a possible solution to reduce the CPU time and to keep an acceptable accuracy. Reaction rates and chemical composition are stored in a lookup table generated from a chemical mechanism and the assumption of a certain flame structure like a perfectly stirred reactor or laminar diffusion flame.

Figure 2 summarizes the way chemistry is tabulated in the proposed approach. The user specifies a chemical mechanism and a range of initial conditions for calculations of a homogeneous constant-pressure reactor in terms of:

- Mixture fraction Z;

- Ambient pressure $p$;

- Initial reactor temperature $T_{u}$;

- Residual gas fraction, or exhaust gas recirculation (EGR);

Based on such quantities, initial chemical composition is computed and the reactor calculation is started. For any specified condition, chemical species equations are solved according to:

$$
\frac{d Y_{i}}{d t}=\dot{\omega}\left(T, p, Y_{1}, \ldots, Y_{n}\right)
$$

FIGURE 2 Generation of the chemistry table based on the homogeneous reactor assumption.

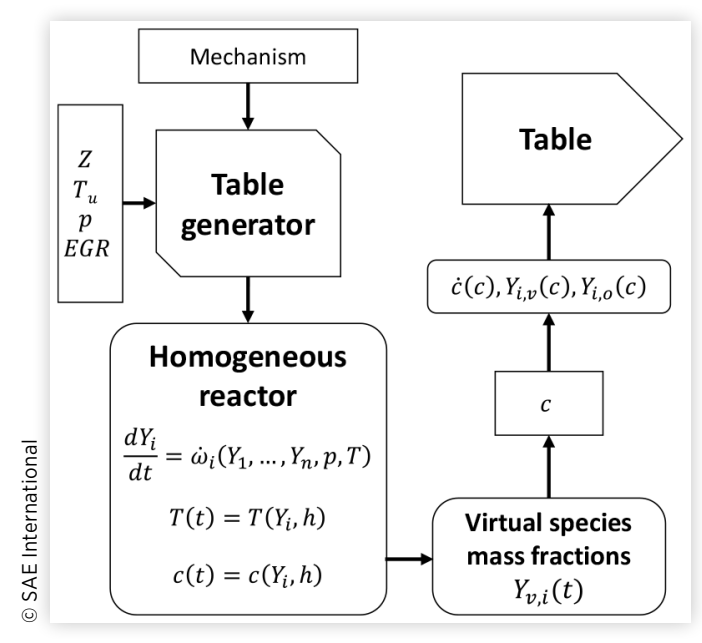

with reactor temperature $T$ computed directly from the initial enthalpy value. After every time step, the progress variable $C$ is evaluated together with the computation of the chemical composition by means of the virtual species approach. Definition of the progress variable follows [44], with $C$ equal to the heat released by combustion, computed as the difference between the current and the initial value of the reactor formation enthalpy, also known as $h_{298}$. At the end of each reactor calculation, progress variable reaction rates, chemical composition, minimum and maximum progress variable values $\left(C_{\min }\right.$ and $\left.C_{\max }\right)$ are stored as function of the discrete values of the normalized progress variable $c$, specified by the user:

$$
c=\frac{C-C_{\min }}{C_{\max }-C_{\min }} .
$$

To avoid excessive memory consumption, only seven virtual species are tabulated for any value of the progress variable $c$. Their mass fractions are computed to preserve the main thermochemical properties of the full set used in the detailed mechanism [45]. The table also includes the mass fractions of chemical species, which are of interest for the user ( $Y_{o}$ in Figure 2), either for post-processing purpose or because they are relevant for the formation of the main pollutants required for the related sub-models.

The homogeneous reactor table can be employed in different ways:

1. directly, providing reaction rates and chemical composition to the CFD solver, with the so-called "tabulated well-mixed" (TWM) approach;

2. embedded into the representative interactive flamelet (RIF) model [46], where flamelet equations are solved only for progress variable and energy, allowing a significant reduction of the computational time (tabulated RIF (TRIF) approach);

3. by generating lookup tables based on more complex flame structures and introducing additional parameters such as the mixture fraction variance or scalar dissipation rate. 
FIGURE 3 Operation of combustion models based on tabulated kinetics [45].

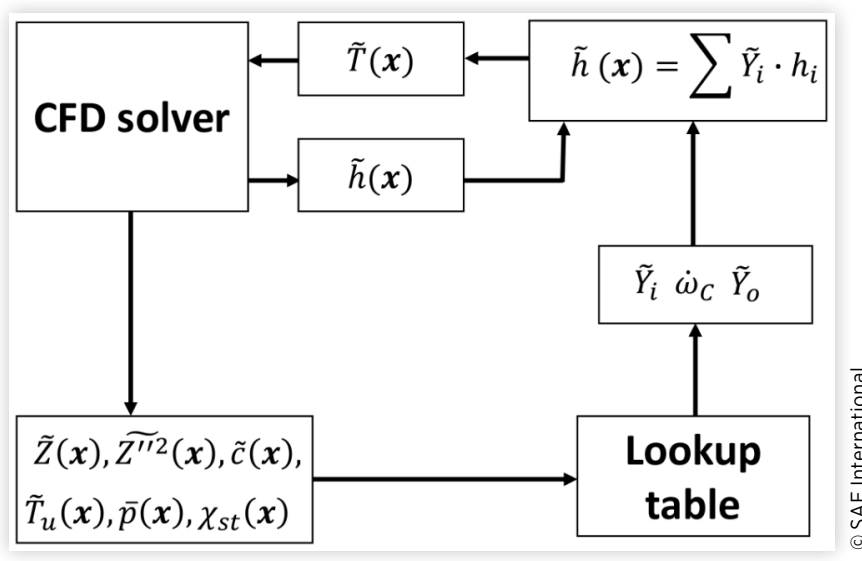

Figure 3 illustrates the operation principle of CFD solvers based on tabulated kinetics. Additional transport equations are solved for mixture fraction $Z$, mixture fraction variance $\widehat{Z^{\prime \prime 2}}$, progress variable $C$ and unburned gas temperature $T_{u}$. In case sub-grid mixing effects are considered, the stoichiometric scalar dissipation rate $\chi_{\text {st }}$ is also computed. The look-up table is accessed with local cell values of $Z, \widetilde{Z^{\prime \prime 2}}, C, p, T_{u}$ and $\chi_{s t}$, and it provides the chemical composition and the progress variable reaction rate to the solver.

In this work, Diesel combustion is simulated with the tabulated flamelet progress variable model (TFPV), whose main purpose is to provide a realistic description of the turbulent diffusion flame, considering turbulence/chemistry interaction, sub-grid mixing and premixed flame propagation. This requires the solution of a transport equation for the progress variable in the CFD domain where the source term depends on local thermodynamic conditions $\left(T_{u}, p\right)$ mixture fraction $Z$, mixture fraction variance $\widetilde{Z^{\prime \prime 2}}$, and stoichiometric scalar dissipation rate $\chi_{s t}$. In this way, the TFPV model is expected to give correct predictions of:

- extinction in the near nozzle region where the scalar dissipation rate is very high;

- re-ignition due to the progress variable convection and diffusion;

- flame stabilization process including effects of both premixed and diffusive flame propagation.

The TFPV library is based on unsteady diffusion flame calculations performed with the TRIF model, similar to refs. $[\underline{4}, \underline{47}, \underline{48}]$, with the so-called "approximated diffusion flames" approach. Generation of the TFPV library is shown in Figure 4: the user specifies a range of temperatures, pressures, and scalar dissipation values for which unsteady diffusion flame calculations are performed using the TRIF model. At any time step, it is possible to estimate the chemical composition in terms of virtual species $Y_{i, v}(Z, t)$, and the progress variable $C(Z, t)$ for the prescribed values of $Z$. TRIF data is then processed at each time step to account for mixture fraction variance. For the specified values of the mixture fraction segregation factor $S_{Z^{\prime \prime 2}}$, the corresponding variance
FIGURE 4 Generation of the tabulated flamelet progress variable (TFPV) table using the TRIF model [45].

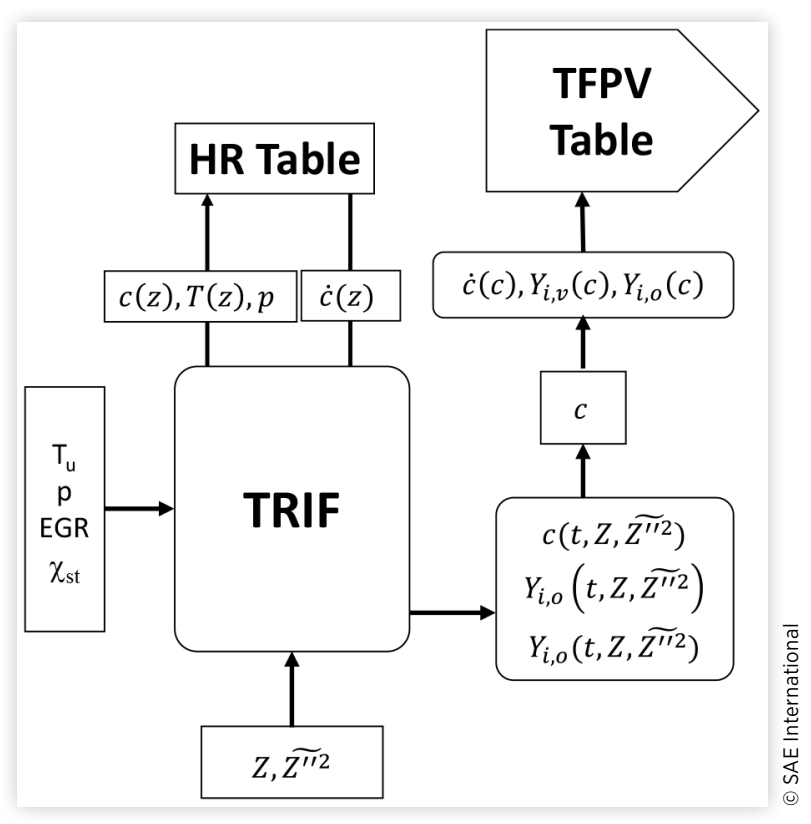

value $\widetilde{Z^{\prime \prime 2}}$ is computed, and progress variable and chemical composition are estimated as follows:

$$
\begin{aligned}
& Y_{i}\left(Z, \widetilde{Z^{\prime \prime 2}}\right)=\int_{0}^{1} Y_{i, T R I F}(Z) \beta\left(Z, \widetilde{Z^{\prime \prime 2}}\right) d Z, \\
& C\left(Z, \widetilde{Z^{\prime \prime 2}}\right)=\int_{0}^{1} C_{T R I F}(Z) \beta\left(Z, \widetilde{Z^{\prime \prime 2}}\right) d Z .
\end{aligned}
$$

At the end of any diffusion flame calculation, for all values of $Z$ and $Z^{\prime \prime 2}$, the progress variable is normalized and its reaction rate is estimated. Computed data are then interpolated for the specified progress variable values to generate the table.

The tabulated mechanism for $\mathrm{n}$-dodecane combustion is the one proposed by Frassoldati et al. [49]], with 96 species and 993 reactions. It was extensively validated with experimental data in a wide range of conditions including flow and stirred reactor experiments, autoignition delay times, laminar flame speeds, and autoignition of isolated fuel droplets in microgravity conditions.

Computational Mesh The main purposes of CFD simulations carried out in this work is:

1. identification of the best setup in terms of mesh and turbulence model to predict Diesel combustion with and without flame-wall interactions;

2. complementing the optical investigation of flame structure and flame-wall interaction.

Due to the fundamental nature of the performed activity, an axi-symmetrical 2D mesh was employed to reduce effects of numerical diffusion, while allowing a higher cell resolution which might be necessary to correctly describe fuel-air mixing

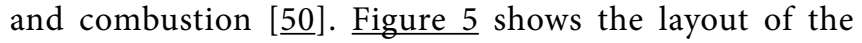


FIGURE 5 Computational meshes adopted for the simulation of the combustion process: (a) free jet; (b) flat wall without boundary layer; (c) flat wall mesh with boundary layers (Figure 5(c) only shows the mesh detail at the flat wall).

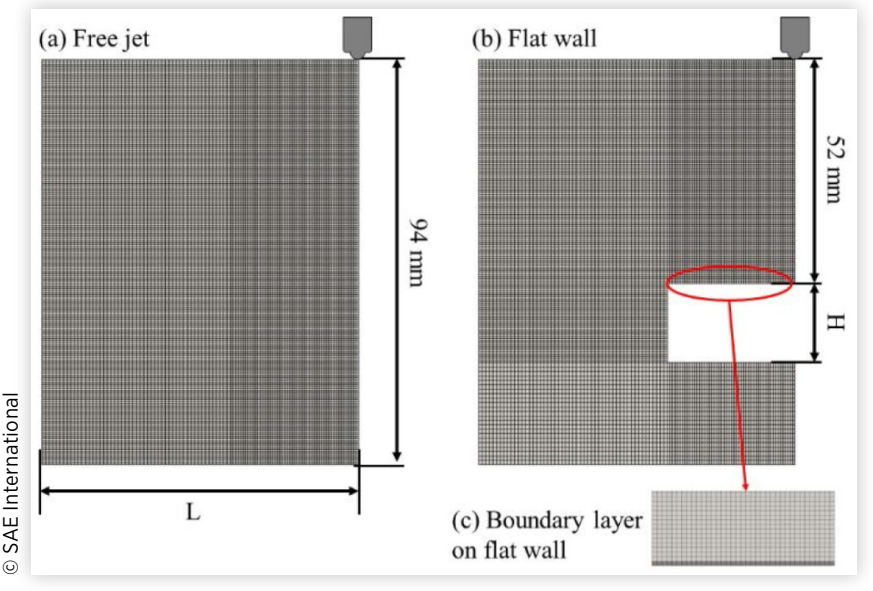

computational meshes used for the free jet, and the flat wall configurations. Combustion modeling with the confined wall will be matter of future studies. The mesh for free jet combustion simulations is illustrated in Figure 5(a): the height corresponds to the distance between the nozzle and the bottom wall while the length $L$ was adjusted to correctly match the experimental value of the vessel volume. Figure 5(b) shows the layout of the computational grid used for flame-wall interaction simulations: the flat wall was placed at a $52 \mathrm{~mm}$ distance from the injector, in accordance with experimental data. The height of the plate was adjusted to account for the whole volume occupied by the insert assembly, which also includes two wallposts. The original vessel volume is approximately $3 \%$ bigger than the one with the flat wall. After a grid-dependency study, the grid size in the region of interest for combustion modeling was set to $0.5 \mathrm{~mm}$ which is slightly more than twice the nozzle diameter value. Preliminary investigations showed that reduction of mesh size to values lower than $0.5 \mathrm{~mm}$ does not produce relevant changes on flame structure and heat release rate. To better describe the main flow features in the flame-wall interaction experiments, effects of the near-wall mesh resolution were also investigated, shown in Figure 5(c). Three different mesh resolutions have been considered.

1. No boundary layer (1 cell layer with $0.5 \mathrm{~mm}$ thickness). This configuration was selected mainly because it is a common practice not use any nearwall refinement in Diesel engine combustion simulation.

2. A layer of $\mathbf{1 0}$ cells at the flat wall, each one with $50 \mu \mathrm{m}$ thickness. With such mesh resolution, both the tested turbulence models ensure a $\mathrm{y}^{+}$values in the 5-50 range which is considered to be sufficient for high-Reynolds flows.

3. A layer of $\mathbf{2 0}$ cells at the flat wall, each one with $25 \mu \mathrm{m}$ thickness. Further reduction of the near-wall mesh resolution allows to exploit the capability of the $\mathrm{k}-\omega$-SST model to describe the near-wall flow without using wall-functions.
TABLE 2 Details of the tested computational meshes.

\begin{tabular}{|c|c|c|c|c|}
\hline & Free jet & $\begin{array}{l}\text { Flat wall } \\
\text { no B.L. }\end{array}$ & $\begin{array}{l}\text { Flat wall } \\
10 \text { cell B.L. }\end{array}$ & $\begin{array}{l}\text { Flat wall } \\
20 \text { cell B.L. }\end{array}$ \\
\hline Cells & 19,000 & 14,400 & 15,000 & 17,000 \\
\hline $\begin{array}{l}\text { Near-wall mesh } \\
\text { resolution }[\mu \mathrm{m}]\end{array}$ & & 500 & 50 & 25 \\
\hline
\end{tabular}

For the sake of completeness, Table 2 reports the mesh size and near-wall resolution employed for the three cases that were modeled. No-slip conditions were applied at all walls in the computational domain. Since this investigation is mainly focused on combustion, the vessel was considered adiabatic, neglecting heat transfer. This will be a matter of study in a future work.

Turbulence Models Two different turbulence models were tested in this work. The first is the standard $\mathrm{k}-\varepsilon$ model [51], which is widely used for Diesel spray combustion simulations. Consistent with previous studies $[\underline{4}, \underline{52}]$, the $\mathrm{C}_{1}$ constant in the $\varepsilon$ equation was changed slightly from 1.44 to 1.5 to correctly reproduce the spray penetration. However, it is well known that the standard k- $\varepsilon$ model is not suitable for jet-wall interaction simulations. As a possible alternative, simulations were also carried out by the k- $\omega$-SST model, which blends the features of $k-\varepsilon$ and $k-\omega$, respectively $[\underline{53}, \underline{54}]$. In the near-wall region, $k-\omega$ and $k-\omega$-SST models behave in the same way, providing a better description of flow curvature and boundary layer development on the flat wall after jet impingement. Far from the walls, k- $\omega$-SST approximates the behavior of the $\mathrm{k}-\varepsilon$ model which is appropriate for free jet flows.

\section{Target Boundary Conditions}

Boundary conditions were selected specifically to permit comparison with conditions provided by the Engine Combustion Network and previously obtained data that are representative working points for heavy-duty applications $[\underline{4}, \underline{13}]$. A single component reference fuel (n-dodecane) is used because of the availability of chemical reaction mechanisms, while closely matching physiochemical properties to Diesel fuel. A summary of the target conditions is listed in Table 3. The A205 condition refers to the ECN Spray A baseline, which is similar in all aspects except for the injector orifice, being $0.205 \mathrm{~mm}$ rather than $0.09 \mathrm{~mm}$. The injector is representative for those in current heavy-duty engines and was subjected to hydro-erosive grinding with a k-factor of 1.5 to suppress cavitation [33]. The two heavy-duty conditions have a similar ambient temperature of $900 \mathrm{~K}$, while density is increased from $22.8 \mathrm{~kg} / \mathrm{m}^{3}$ to $40 \mathrm{~kg} / \mathrm{m}^{3}$ with an injection pressure of $80 \mathrm{MPa}$ and $160 \mathrm{MPa}$ for C3 and C4, respectively. Ambient oxygen concentration is increased from a moderate amount of EGR at $15 \% \mathrm{O}_{2}$, to nearly atmospheric at $20.5 \% \mathrm{O}_{2}$. To keep the amount of fuel injected similar, the injection duration for the 160-MPa case was decreased from 5.2 to $3.8 \mathrm{~ms}$. Injection durations listed in Table 3 are deduced from mass-flow measurements with a back-pressure of $6 \mathrm{MPa}$. 
TABLE 3 Details of the boundary conditions that have been investigated with the $0.205 \mathrm{~mm}$ single orifice injector.

\begin{tabular}{|c|c|c|c|}
\hline & A205 & C3 & C4 \\
\hline $\begin{array}{l}\text { Ambient temperature } \\
{[\mathrm{K}]}\end{array}$ & \multicolumn{3}{|c|}{900} \\
\hline $\begin{array}{l}\text { Ambient density } \\
{\left[\mathrm{kg} / \mathrm{m}^{3}\right]}\end{array}$ & 22.8 & 40 & 40 \\
\hline $\begin{array}{l}\text { Approximate pressure } \\
\text { [MPa] }\end{array}$ & 6 & 10.5 & 10.5 \\
\hline Ambient $\mathrm{O}_{2}[\mathrm{vol} \%]$ & 15 & 20.5 & 20.5 \\
\hline $\begin{array}{l}\text { Fuel injection pressure } \\
{[\mathrm{MPa}]}\end{array}$ & 150 & 80 & 160 \\
\hline Fuel temperature $[\mathrm{K}]$ & \multicolumn{3}{|c|}{363} \\
\hline Injection duration [ms] & 5.0 & 5.2 & 3.8 \\
\hline Injected fuel mass [mg] & 63 & 46.8 & 49 \\
\hline $\begin{array}{l}\text { Discharge coefficient } \\
C_{d}{ }^{a}[-]\end{array}$ & $0.84(0.89)$ & $0.89(0.92)$ & $0.86(0.90)$ \\
\hline Area coefficient $c_{a}[-]$ & 0.91 & 0.99 & 0.97 \\
\hline
\end{tabular}

a The discharge coefficient was determined using the average mass flow between $0.5 \mathrm{~ms}$ and $1.5 \mathrm{~ms}$ after start of injection for initializing the 1D spray model that is used to evaluate the equivalence ratios shortly after ignition. The value between brackets indicates the discharge coefficient between $0.5 \mathrm{~ms}$ and $4.5 \mathrm{~ms}$ after start of injection.

\section{Results and Discussion}

The results of this work are presented in four sections. The first section contains a discussion of the signal origin for light that is collected using a high-speed intensified camera with a set of optical bandpass filters targeted at $\mathrm{OH}^{*}$ chemiluminescence. In the second section, the early flame development is evaluated using both high- and low-temperature combustion markers. In the third section, the global high-temperature reactions are discussed using both the $\mathrm{OH}^{*}$ radical, as well as the apparent heat release rates as obtained by experiments and simulations. The final section shows preliminary results obtained for flame-wall interaction cases using both wall inserts.

\section{$\mathrm{OH}^{*}$ Chemiluminescence Signal Analysis}

As noted by Higgins et al. [29], $\mathrm{OH}^{*}$ chemiluminescence and soot incandescence can have comparable contributions to the luminescence of the downstream portion of a spray when using optical filters. They came to this conclusion by using filters with a central wavelength of 310 and $532 \mathrm{~nm}(10 \mathrm{~nm}$ FWHM), and considering Planck's law for soot radiation at temperatures between 2000 and $2200 \mathrm{~K}$. A similar approach is used in this analysis, although the selected filters have central wavelengths that are only separated by $20 \mathrm{~nm}$. The upper graph in Figure 6 shows the net transmission of the $\mathrm{OH}^{*}$ chemiluminescence filter pack, and the soot filter pack. Comparing these filter transmissions to a simulated $\mathrm{OH}$ emission spectrum at $2000 \mathrm{~K}$ and $6 \mathrm{MPa}$ shows that the soot filter pack should not transmit any $\mathrm{OH}^{*}$ chemiluminescence. Using the integrated area underneath the two filter-pack
FIGURE $6 \mathrm{OH}^{*}$ chemiluminescence spectrum with the efficiencies of a dedicated $\mathrm{OH}^{*}$ chemiluminescence filter pack, and a soot filter pack with similar transmission but spectrally shifted to the red (upper panel). Spectral emission of $\mathrm{OH}^{*}$ based on LIFBASE simulations at $2000 \mathrm{~K}$ and $6 \mathrm{MPa}$ [55]. Results from Planck's law at $2100 \mathrm{~K}$ are shown in a red curve, while the quantum efficiency of the photocathode is shown in cyan. The bottom panel shows the optical density of the filter packs over the entire relevant spectrum, together with the quantum efficiency of the photocathode.

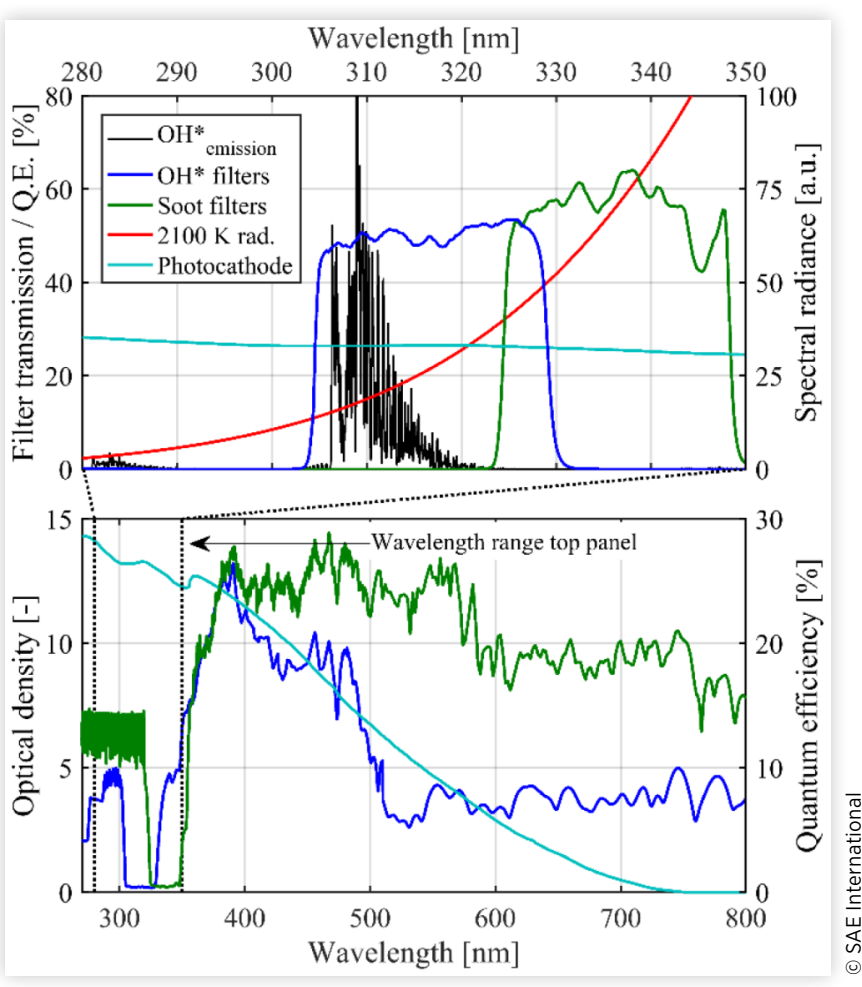

curves, and the results from Planck's law in combination with the slightly decreasing quantum efficiency of the photocathode, a ratio of 2.34 is found in terms of soot transmission for the two different filter packs. Therefore, if one were to correct for the black body radiation at $2100 \mathrm{~K}$ based on these specified filter transmissions, this ratio should be taken into account.

Considering that optical filters have a non-zero transmission at the wavelengths outside from the design range, however, unintended signal might contribute more than expected. Especially since soot incandescence can be intense, and present across the entire spectrum, a minor transmissionleak of a filter may result in accumulation of spurious signal over that entire range. The lower graph of Figure 6 shows the filter specifications in terms of optical density over the entire relevant wavelength range, which is limited by the quantum efficiency of the photocathode $(\lambda<760 \mathrm{~nm})$. Note that optical density is more appropriate to describe the undesired transmission, being defined as the base- 10 logarithm of the transmission. This means that for instance, an OD of 0,1 , and 2 correspond to a transmission of $100 \%, 10 \%$ and $1 \%$, respectively. As can be seen from this graph, the optical density is rather high for the $\mathrm{OH}^{*}$ filter pack between $340 \mathrm{~nm}$ and 
$470 \mathrm{~nm}$, but it decreases down to about 4 in a range which is still relevant with the used photocathode. The soot filters have a much higher OD over the entire range above $360 \mathrm{~nm}$. The transmission ratio analysis as above can be performed over the entirely shown spectral range, giving a more realistic value for the integrated soot transmission. Using the product of the transmission, the photocathode and the radiation predicted by Planck's law at $2100 \mathrm{~K}$ over the entire range, a ratio of 1.06 is found when comparing the $\mathrm{OH}^{*}$ filter pack to the soot filter pack. The large difference with the first exercise is solely caused by the finite OD of the soot filters at longer wavelengths.

Note that the black body temperature may play a crucial role in the computation of the obtained transmission ratios. Reducing the temperature down to $2000 \mathrm{~K}$, gives a ratio of 2.50 in the desired transmission range and a ratio of 0.87 in the high-OD range. Similarly, when a black body temperature of $2200 \mathrm{~K}$ is used, the ratios change to 2.20 and 1.22 , respectively. This shows how incandescence transmission in the design range is always higher for the soot filter, while it may be either higher or lower over the total spectral range, depending on temperature.

The upper left panels of Figure 7 represent signal intensities obtained with the different filter sets and displayed in a false color scale. The experiments were performed with the $0.205-\mathrm{mm}$ heavy-duty injector at $900 \mathrm{~K}$ and $22.8 \mathrm{~kg} / \mathrm{m}^{3}$ with an injection pressure of $150 \mathrm{MPa}$; settings for the $\mathrm{OH}^{*}$ imaging system were similar for the two filter sets. By using the ratio of 1.06 determined from the data in the lower panel of Figure 7, the signal intensities from the $\mathrm{OH}^{*}$ filters and the soot filters are scaled such that they are corrected for incandescence in the part that is intended to transmit signal, as well as the region with increased optical density. The lower left panel shows the amplified residual $\mathrm{OH}^{*}$ chemiluminescence signal after subtracting the results obtained with the soot filters. From this panel, it appears that the signal downstream of the lift-off region rapidly decreases, suggesting that most of the signal in this region of the original $\mathrm{OH}^{*}$ chemiluminescence images is in fact originating from soot incandescence at either higher wavelengths or within the designed filter range.

To further determine the origin of the light from a spray, an ICCD was equipped with a spectrograph and the slit was aligned parallel to the spray axis. An offset of approximately $2 \mathrm{~mm}$ was used to image the bright lobes at the lift-off length, shown in the bottom right panel of Figure 7. The results presented here correspond to a $0.09-\mathrm{mm}$ Spray A injector, and the axial- and radial scale is changed to accommodate the region of interest for the spray. Despite the different orifice diameter, the flames are relatively similar in terms of flame structure, and are likely to exhibit similar features. Note that the ambient conditions are nominally the same, and that the lift-offlength is approximately proportional to orifice diameter to the power 0.34 [56]. Using a grating with 1200 grooves $/ \mathrm{mm}$ and a long exposure $(4.5 \mathrm{~ms}$, single-shot during the quasisteady phase of the spray), the spectral envelope of $\mathrm{OH}^{*}$

FIGURE 7 The upper left panels show time- and ensemble averaged results from the 0.205-mm injector obtained using the $\mathrm{OH}^{*}$ filters, and the soot filters in a false-color scale, respectively. The result after subtracting them is shown in the lower left panel, to emphasize the locations where $\mathrm{OH}^{*}$ chemiluminescence dominates the overall signal. The upper right panel shows a spectrally resolved line image (see lower panel for location) parallel to the spray axis for the 0.09-mm injector recorded with a 1200 grooves/mm grating. The second panel on the right shows a similar image over a larger wavelength range, revealing additional chemiluminescence originating from low-temperature chemistry, and soot as well. The signature of $\mathrm{OH}^{*}$ is identified by a dashed white rectangle. Note that a gamma correction of 0.08 was applied to reveal the relatively faint chemiluminescence, when compared to the intense soot radiation. The red line in the bottom right panel illustrates the location where the single-shot spectra were recorded with the $0.09-\mathrm{mm}$ injector
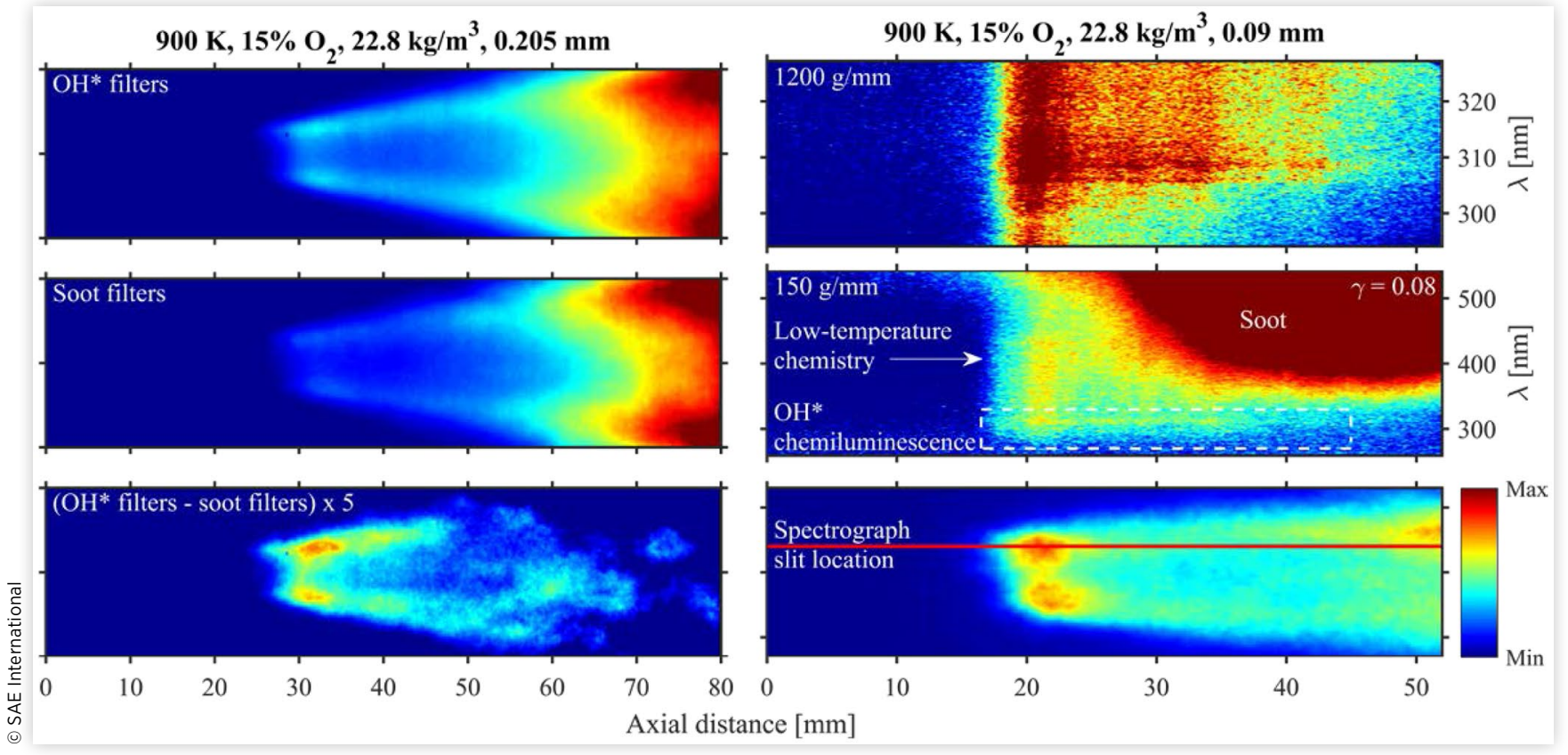

(c) 2018 SAE International. All Rights Reserved. 
chemiluminescence is evident, with a band head around $309 \mathrm{~nm}$, and a hint of the slightly weaker head around $307 \mathrm{~nm}$. The bright lobe at the lift-off location can clearly be identified in the spectrum as well. Moving downstream, the $\mathrm{OH}^{*}$ intensity rapidly decreases and approaches the noise limit at approximately $50 \mathrm{~mm}$. At the same time, the integrated intensity along the indicated slit position in the lower right panel is certainly increasing downstream of $45 \mathrm{~mm}$, despite a small reduction of intensity owing to the cone angle of the spray at first.

In the second panel on the right, a similar single-shot spectrum is shown with a 150 -grooves/mm grating and an exposure time of $0.24 \mathrm{~ms}$ during the quasi-steady phase of the spray. A gamma correction of 0.08 and an intensity threshold were applied for this case to reduce and limit the relatively intense signal originating from incandescent soot, respectively. The signature of $\mathrm{OH}^{*}$ emission is still visible around 309 and $307 \mathrm{~nm}$ (identified by a dashed white rectangle) and again disappears at around $40 \mathrm{~mm}$ downstream from the injector location. Additionally, upstream chemiluminescence originating from low-temperature chemistry is detected in a broad region around $400 \mathrm{~nm}$, until it is flooded by incandescence starting from spatial locations around $25 \mathrm{~mm}$ and further downstream. The location where incandescence starts corresponds well to regions identified in a soot study of a nominally identical spray flame by Cenker et al. [ㅁ].

The fact that numerical models attempt to reproduce the flame structure of spray flames based on images recorded through optical filters identifies the significance of the two independent strategies shown here. However, a more detailed study to characterize the effect of ambient conditions on the ratio would be required to provide more guidelines. The fact that the signal in the lift-off region is predominantly originating from $\mathrm{OH}^{*}$ gives confidence. However, the use of traditional combustion indicators such as the lift-off length and light-based ignition delay for model validation. A more elaborate and detailed study using the two approaches shown in Figure 7 could provide new guidelines for interpretation of the conventional $\mathrm{OH}^{*}$ chemiluminescence images.

\section{Early Flame Development}

Several studies have pointed out the interference by PAH fluorescence and soot LII in formaldehyde PLIF experiments of Diesel jets $[\underline{25}, \underline{58}]$. In this study, the fuel spray is visualized shortly after auto-ignition, before soot is being formed. Therefore, such interference can be evaded while the formaldehyde distribution has already reached a quasi-steady state at that moment in time [34, 37]. Similarly, by evaluating the early flame-development, $\mathrm{OH}^{*}$ images are less likely to be influenced by the incandescence contributions as described above. However, due to the moderately sooting heavy-duty conditions, it is expected that a significant part of the highdensity cases is still influenced by PAH fluorescence after all, as will be discussed below.

Computed and experimental combustion indicators are summarized in Table 4. As the experimental $\mathrm{OH}^{*}$ chemiluminescence recordings were tuned such that they utilize the entire dynamic range of the camera without saturating, they are not sensitive enough to capture the faint signal during the
TABLE 4 Ignition delay (ID) times and flame lift-off length (FLOL) values for the different cases studied in this work. Numerical results include both turbulence models that were used in this study. Experimental ignition delay values are determined using both high-speed chemiluminescence imaging and pressure data.

\begin{tabular}{|c|c|c|c|}
\hline & A205 & FPT C3 & FPT C4 \\
\hline ID - pressure [ms] & $0.38 \pm 0.02$ & $0.32 \pm 0.04$ & $0.22 \pm 0.04$ \\
\hline ID - OH* fit ${ }^{\mathrm{a}}[\mathrm{ms}]$ & $0.56 \pm 0.05$ & $0.43 \pm 0.06$ & $0.39 \pm 0.07$ \\
\hline ID - k- $\varepsilon[\mathrm{ms}]$ & 0.47 & 0.3 & \\
\hline ID - k- $\omega$-SST [ms] & 0.43 & 0.27 & \\
\hline $\mathrm{FLOL}-\mathrm{OH}^{*}[\mathrm{~mm}]$ & $27.89 \pm 0.51$ & $12.19 \pm 0.5$ & $13.93 \pm 0.66$ \\
\hline FLOL - k- $\varepsilon[\mathrm{mm}]$ & 26.5 & 2 & \\
\hline FLOL - k- $\omega$-SST [mm] & 24.5 & 2.5 & \\
\hline
\end{tabular}

a The ignition delay values determined from the high-speed chemiluminescence images are expected to be significantly biased toward a relatively long ignition delay because of a reduced sensitivity of the imaging system to accommodate the intense soot radiation within the dynamic range of the camera.

first phase of the high-temperature ignition. Therefore, the pressure-based ignition delay values are likely to be more accurate experimental indicators, and therefore more suitable for model validation. In the simulations, the lift-off length is computed according to the ECN definition of minimum axial distance from the nozzle where the $\mathrm{OH}$ mass fraction is $14 \%$ of the maximum value in the CFD domain [13]. No big differences were found by either changing the $\mathrm{OH}$ threshold value or using the alternative metrics based temperature. Numerical ignition delay is defined as the instant where maximum computed pressure rise rate is found. For both cases, the ignition delay is rather well predicted.

The left panels of Figure 8 show ensemble-averaged experimental $\mathrm{CH}_{2} \mathrm{O}$ PLIF results and $\mathrm{OH}^{*}$ chemiluminescence recordings using green and red color-coding, respectively. The time after start of injection (aSOI) is $0.7 \mathrm{~ms}$ for A205, while it is $0.55 \mathrm{~ms}$ for the two high-density conditions. Comparing the experimental $\mathrm{CH}_{2} \mathrm{O}$ distribution of the $0.205-\mathrm{mm}$ injector at $22.8 \mathrm{~kg} / \mathrm{m}^{3}$ to the results obtained with an injector that has an orifice diameter of $0.09 \mathrm{~mm}$ (e.g. [ $\underline{34}, \underline{35}, \underline{37}, \underline{59}])$ shows a large similarity, although at a larger scale. In previous studies, it was shown how the downstream formaldehyde distribution is contained within the high-temperature periphery of the jet $[\underline{34}, \underline{58}]$, and recall the proportionality of the lift-off length to orifice diameter [56]. Although line-of-sight integrated, the $\mathrm{OH}^{*}$ chemiluminescence distribution still encompasses the $\mathrm{CH}_{2} \mathrm{O}$ region as the signal is stronger at radial distances further from the spray axis. However, a faint PLIF intensity can also be distinguished at these locations, which might indicate early zones with small amounts of PAH. Note that a significant overlap of sufficient $\mathrm{OH}^{*}$ chemiluminescence and PLIF intensity results in a yellow color. Given that PAH might readily be present at this time, it is possible that the most downstream signal either contains or consists of PAH as well. Strong elastic scattering from the liquid fuel is observed near the injector nozzle, but a sudden radial expansion around $20 \mathrm{~mm}$ indicates the onset of formaldehyde. At inert conditions, the A205 case produced a liquid length of $26.4 \mathrm{~mm}$ [4], reaching rather far beyond this onset. Assuming that a similar 
FIGURE 8 Comparison between experimental (left panels) and numerical (right panels) fields of OH and formaldehyde. The results are color-coded, using green for $\mathrm{CH}_{2} \mathrm{O}$ fields, red for $\mathrm{OH}$ (numerical) and $\mathrm{OH}^{*}$ (experimental) fields, and blue for $\mathrm{C}_{2} \mathrm{H}_{2}$ in simulations. The $\mathrm{k}-\varepsilon$ turbulence model was used for the numerical simulations, and boundary conditions are indicated in the central panels for ease of interpretation. For the upper left panel, the laser sheet reached further upstream, resulting in an increased amount of elastic scattering from liquid fuel. The central panels show equivalence ratio predictions from the 1D spray model [32]. See text for additional details.

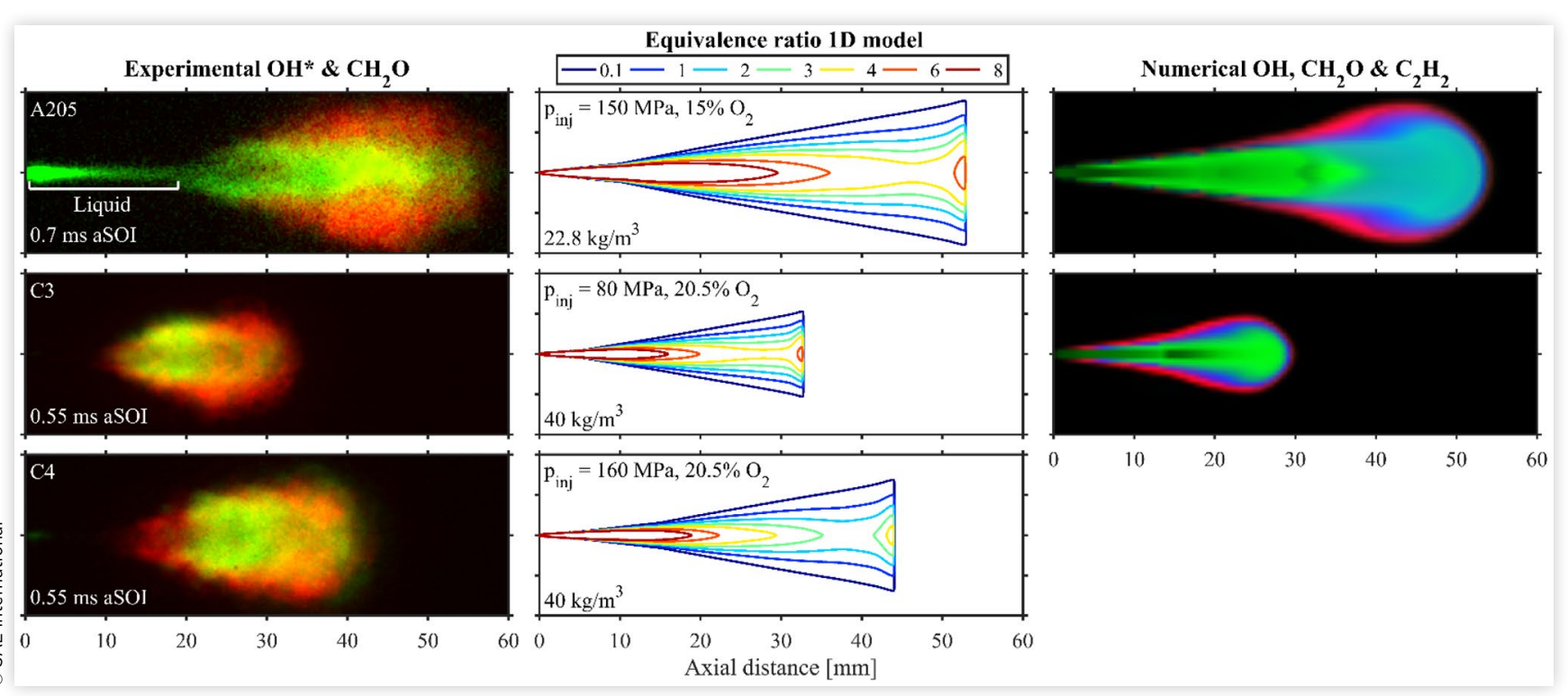

liquid length is sustained in the reactive case, this illustrates how formaldehyde may surround the rich core where liquid fuel is still present. In several modeling results for the $0.09-\mathrm{mm}$ Spray A conditions, formaldehyde is also predicted to surround the liquid core, reaching much further upstream compared to experimental observations $[\underline{9}, \underline{34}, \underline{35}, \underline{37}, \underline{60}]$. Potentially, low number densities in combination with turbulent fluctuations of the liquid core, and elastic scattering of the laser light off the liquid fuel obscure these observations for a smaller injector orifice.

At the high-density conditions shown in Figure 8, $\mathrm{OH}^{*}$ chemiluminescence at first appears upstream of the presumed experimental formaldehyde signal. Although something similar was shown for moderate-soot conditions with a $0.1 \mathrm{~mm}$ injector by Idicheria et al. [58], the separation observed here is much more pronounced, especially for the case with an injection pressure of $160 \mathrm{MPa}$ (C4). To avoid severe elastic scattering from the liquid fuel compared to the upper panel, however, the laser sheet was translated slightly upstream of approximately $10 \mathrm{~mm}$ from the injector orifice, thus reducing the effective fluence in the region near the lift-off.

The high-temperature flame lift-off length has been shown to correlate well with the residence time that a fuel parcel is subjected to from the injector to that location [61]. In consequence of the shorter ignition delay by the highdensity ambient and increased ambient oxygen concentration, residence times decrease significantly for the heavy-duty boundary conditions (see Table 4). In addition, spray penetration is reduced owing to the increased ambient density, restricting the fuel parcels traveling downstream. As a consequence, the lift-off length for both high-density conditions is significantly reduced. Due to the large orifice injector, liquid length values at non-reacting conditions are still approaching
$20 \mathrm{~mm}$ for these conditions [4]. With a relatively short flame lift-off close to the spray axis, and a long liquid length, upstream formaldehyde is restricted to a very narrow region, just encompassing the liquid region. Again, this is expected to result in rather low number densities for formaldehyde in this region.

The central column of Figure 8 presents the equivalence ratio contours obtained by the one-dimensional model of Musculus et al. [32], using the inert spray penetration and injector characteristics for the corresponding conditions [4]. Since the model does not include chemical kinetics, it does not take into account the radial expansion due to combustion $[\underline{59}, \underline{62}]$. However, expansion is expected to be minimal shortly after second stage ignition [62], and the model is still expected to give a reasonable prediction for equivalence ratio, identifying differences arising from the different ambient gas conditions. Formaldehyde signal in the low-density case (top panel of the left column) is found in a corresponding region roughly confined by an equivalence ratio between 1 and 8 , as shown by the $1 \mathrm{D}$ model results. The impact caused by the oxygen concentration is well represented in these figures, equivalence ratios being strongly reduced for the high-oxygen concentration cases. For these high-density cases, experimental PLIF intensity is found in relatively leaner regions as well. The fact that it reaches the jet periphery, indicated by $\mathrm{OH}^{*}$ in the left panels of Figure 8, suggests that the origin of the fluorescence is more likely to be $\mathrm{PAH}$ than $\mathrm{CH}_{2} \mathrm{O}$ at that time. However, both high-density cases also show reduced signal intensities near the injector axis, in the central portion of the spray, while results from smaller injectors show a radially invariant $\mathrm{PAH}$ signal $[34,35, \underline{37}, \underline{58}]$. Furthermore, the distribution narrows around $25 \mathrm{~mm}$ and $35 \mathrm{~mm}$ downstream of the injector for the low- and high-injection pressure, respectively, which is typical 
for formaldehyde distributions. Based on these observations, and given that the orifice is relatively large with formaldehyde expected to be present in regions that are more fuel rich compared to PAHs, PLIF signal close to the spray axis most likely contains a contribution originating from $\mathrm{CH}_{2} \mathrm{O}$. Spectrally resolved measurements, possibly combining onand off-resonant excitation [35], could be required to resolve this issue.

The numerical results in the upper right panel of Figure 8 show $\mathrm{CH}_{2} \mathrm{O}$ (green), $\mathrm{OH}$ (red), and $\mathrm{C}_{2} \mathrm{H}_{2}$ (blue) at $0.7 \mathrm{~ms}$, right after ignition. All species are normalized individually to highlight their distribution, rather than absolute number densities. $\mathrm{OH}$ distributions were used in this case, as $\mathrm{OH}^{*}$ was not available in the tested mechanism. In the A205 case, it is possible to see that formaldehyde is mainly located in the core of the jet while $\mathrm{OH}$ can be found at the periphery. $\mathrm{C}_{2} \mathrm{H}_{2}$ is used as a soot precursor in many soot models. As such, it can be regarded as an indicator for $\mathrm{PAH}$, and combined with $\mathrm{CH}_{2} \mathrm{O}$ it provides more insight in experimentally obtained PLIF images. The qualitative agreement between computed and experimental species distribution for the A205 condition is acceptable. With good predictions of combustion indicators for this boundary condition (Table 4), the simulations confirm the presence of $\mathrm{PAH}$ and the overlap with formaldehyde (represented as a cyan colored region). As hypothesized, the $\mathrm{C}_{2} \mathrm{H}_{2}$ distribution is indeed also found at a larger radial distance from the spray axis, towards the periphery of the jet. However, $\mathrm{OH}$ and formaldehyde appear even close to the nozzle according to the simulations, where $\chi_{s t}$ is generally high but not enough to prevent first-stage ignition. The reason for this is the presence of partially oxidized species in the spray, and more work is necessary to improve the combustion model.

For what concerns the predictions of the $\mathrm{C} 3$ case, it is possible to see in Figure 8 that both higher oxygen concentration and increased density make the flame more compact around the jet axis. Due to the higher mixture reactivity, both species appear closer to the injector compared to the A205 conditions. The simulation correctly describes the qualitative changes in the species distribution but in this case both $\mathrm{OH}$ and $\mathrm{CH}_{2} \mathrm{O}$ can be found immediately at the nozzle exit because the combustion model is not able to predict the extinction of the flame accurately, even in presence of very high values of the stoichiometric scalar dissipation rate. More importantly, simulations clearly show the change of overlapping formaldehyde and $\mathrm{C}_{2} \mathrm{H}_{2}$ starting at a certain distance from the nozzle (A205 case), to the co-existence of these species at certain axial positions, but with a more distinct radial separation. Again, this shows that the interference by PAH PLIF is likely in the experimental results, and is more difficult to distinguish from formaldehyde for the high-density cases.

Based on the simulated cases, the following aspects were identified to be investigated in future numerical work;

- effect of flamelet mesh resolution for generation of the TFPV table. In this work, a 100-nodes grid was used, but a finer mesh is expected to improve prediction of both partial and full flamelet extinction;

- inclusion of fuel evaporation effects on the mixture fraction variance transport equation [63], which will produce higher values of $\chi_{s t}$ in the near nozzle region.
To investigate the $\mathrm{CH}_{2} \mathrm{O}$ and $\mathrm{PAH}$ distributions in more detail, a single-shot image corresponding to the bottom-left panel of Figure 9 , and a low-density case for a more mature spray where studied. The upper panel of Figure 9 shows a single-shot result of simultaneously acquired $\mathrm{OH}^{*}$ chemiluminescence (red) and PLIF results (green), overlaid with liquid and vapor penetration obtained from inert experiments in light-blue and white contours, respectively [4]]. Similar to the ensembleaveraged results in Figure 8 , the composition illustrates how the high-temperature $\mathrm{OH}^{*}$ structure encompasses the PLIF results. Furthermore, the combination with the vapor and liquid boundaries obtained from inert experiments clearly show some of the aforementioned phenomena. First of all, radial expansion due to combustion is limited, and doesn't appear until roughly twice the distance of the flame lift-off. The liquid core obtained from inert experiments is penetrating far into the flame cone, while the separation of the vapor contour from the liquid contour coincides with $\mathrm{OH}^{*}$ chemiluminescence signal. Because of the flame taking up this space, there is indeed negligible space left for first-stage ignition products, although they obviously need to precede secondstage ignition. Between 18 and $22 \mathrm{~mm}$ downstream from the injector, PLIF signal is found surrounding the liquid core

FIGURE 9 The upper panel shows a single-shot result of simultaneous PLIF (green) and $\mathrm{OH}^{*}$ chemiluminescence (red) at $0.55 \mathrm{~ms}$ aSOI, illustrating the upstream location of the $\mathrm{OH}^{*}$ signal with respect to the detected fluorescence signal for the $\mathrm{C} 4$ condition. The light-blue and white contours represent the ensemble averaged liquid and vapor boundaries from inert experiments, respectively. The bottom panel shows ensemble averaged PLIF results for the A205 case with a flat plane wall insert at $1 \mathrm{~ms}$ aSOI. A gamma correction of 0.05 was applied to the lower panel reduce the signal downstream. See text for additional details.
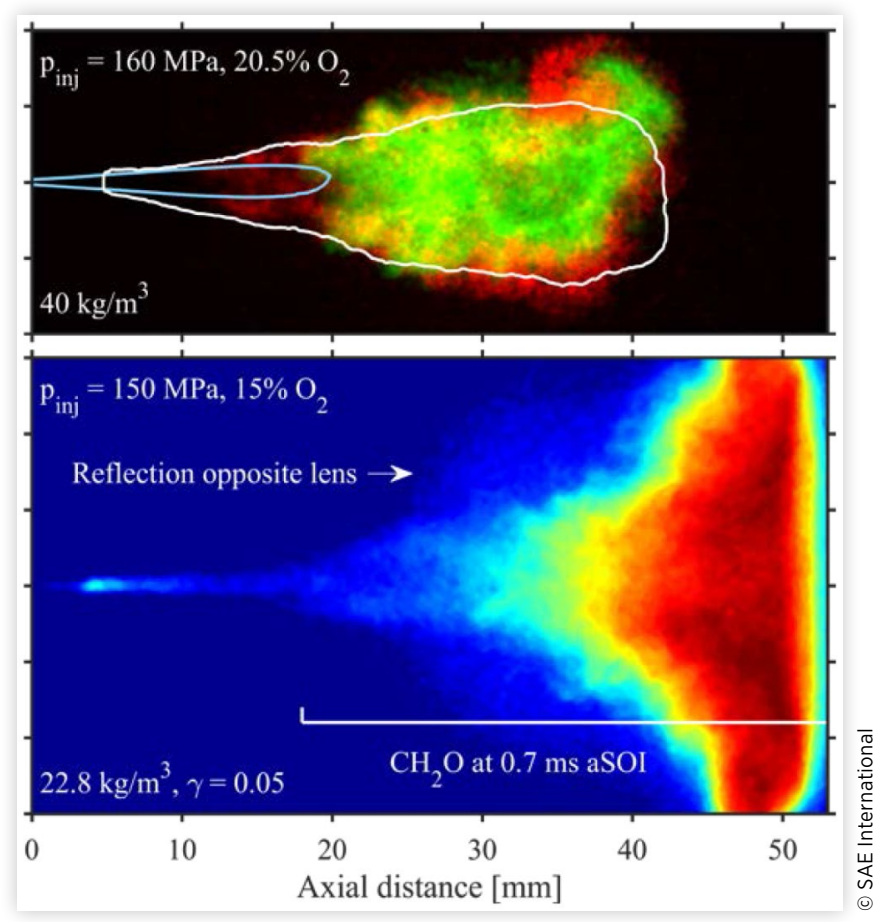

(c) 2018 SAE International. All Rights Reserved. 
while being contained mostly within the high-temperature flame front. Between 22 and $25 \mathrm{~mm}$, the PLIF signal seems to expand radially while the signal strength increases, potentially corresponding to the onset of PAH PLIF for this particular result.

In the lower panel of Figure 9, PLIF results from the lowdensity case are shown, $1 \mathrm{~ms}$ after the start of injection. A plane wall insert is placed at $52.5 \mathrm{~mm}$ downstream from the injector in this case. Here, a gamma correction of 0.05 was applied to reduce the signal intensity not corresponding to formaldehyde fluorescence. The effect of the wall insert will be discussed in more detail in the final section. Due to the strong signal, a faint disk-shaped reflection from the opposite lens (see Figure 1) can be distinguished, indicated in the image. The purpose of this panel, however, is to illustrate how most of the presumed $\mathrm{CH}_{2} \mathrm{O}$ signal (indicated by a white bracket) from the upper left panel of Figure 8 is now obscured by PAH PLIF and soot incandescence. This confirms how in downstream regions of large orifice injectors, it is likely that $\mathrm{CH}_{2} \mathrm{O}$ is being obscured by a significantly stronger $\mathrm{PAH}$ signal over a relatively large portion of the spray. The signal close to the spray axis in these regions might still contain a distinguishable contribution by formaldehyde, which transits to PAH fluorescence when moving towards the periphery of the jet in radial direction. However, such a conclusion cannot be deduced based on this image. For proper distinction between formaldehyde and $\mathrm{PAH}$ in future experiments with large orifice injectors, an on- and off-resonant imaging strategy might be required to provide more conclusive results $[\underline{35}, \underline{36}]$.

\section{Global High-Temperature Reactions}

Global development of the high-temperature reactions was studied in more detail using the high-speed diagnostic techniques. The upper panel of Figure 10 shows contour plots derived from the high-speed $\mathrm{OH}^{*}$ data. Similar to previous studies, the chemiluminescence intensity $(I)$ is integrated in the radial direction of the spray $(y)$ to derive the temporal evolution of the intensity along the spray axis $(x)$ as a function of time $(t)$,

$$
I(x, t)=\int_{y_{\min }}^{y_{\max }} I(x, y, t) d y .
$$

After this integration, $\mathrm{OH}^{*}$ contours are selected such that the solid lines in the most upstream part (lower part of the panel) represent the quasi-steady lift-offlength values presented in Table 4. A more in-depth discussion of displaying the highspeed data using this method is given in a previous publication [34]. All cases show a relatively large region of ignition, characterized by the large axial range over which signal appears at the time of ignition. After the end of injection, all cases show combustion recession as well, although it is more pronounced for the low-density A205 case due to the more sensitive dynamic range settings for these experiments. For the so-called soot contours, a $6 \%$ higher intensity was used in all cases. This corresponds approximately to the first location in the upper

\section{FIGURE 10 Comparison between high-speed $\mathrm{OH}^{*}$} chemiluminescence data in the top panel, and experimental AHRR in the bottom panel. From the $\mathrm{OH}^{*}$ chemiluminescence, a threshold based on the signal at the quasi-steady lift-off was used, as well as a second threshold that matches with the location in which soot presumably becomes dominant. Experimental spray penetration curves from inert conditions are shown in dotted lines, showing different expansion behavior for different ambient conditions. See text for additional details.

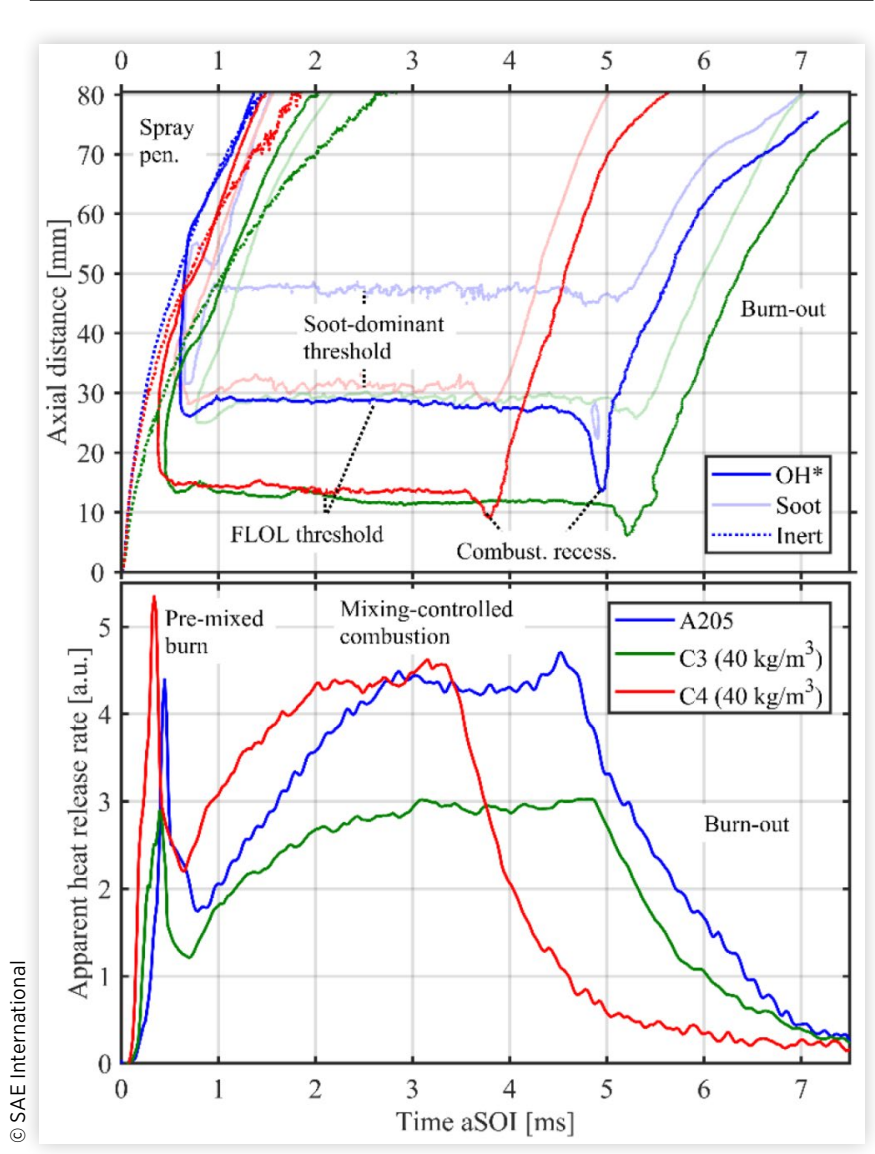

left panel of Figure 7 where the downstream intensity on the spray axis matches the maximum on-axis intensity that was found at the lift-off, which also holds for the high-density cases. In the lower left panel of Figure 7, this represents a region where soot starts to be more dominant than the $\mathrm{OH}^{*}$ signal, which is why they are referred to as soot contours in Figure 10. This indicates how the high-density cases are already likely to be producing significant amounts of soot at the location where the A205-case flame stabilized. The dotted lines are obtained from previous inert spray penetration experiments, showing how the flame penetration approximately matches the inert penetration for all cases during the initial phase. For the highdensity cases, the flame penetrates faster than the vapor-phase fuel after a specific time, due to the combustion-induced expansion [62]. This is most prominently observed for the case which has the lowest penetration rate, presumably caused by the relatively large flames within a limited field of view.

The AHRR curves clearly demonstrate the differences in ignition delay and give a good indication of the relative 
amount of heat released during the pre-mixed burn, being twice as high for the $160-\mathrm{MPa}$ injection versus the $80-\mathrm{MPa}$ injection at the high density. Detection of the first $\mathrm{OH}^{*}$ chemiluminescence closely follows the peak heat release during the pre-mixed burn. All cases have reached a mixing-controlled quasi-steady heat release rate after approximately $3 \mathrm{~ms}$, although the $\mathrm{C} 4$ case stabilizes earlier. Higher injection pressures help to reduce the time to reach the mixing-controlled combustion region at the high-density condition. This is not caused by an increased mixing distribution, but rather related to the faster penetration and, therefore, the shorter history of mixing [64]. The difference between A205 and C4 is again affected by a faster penetration, and a significant influence in equivalence ratio due to the higher oxygen percentage in the latter. In all cases the AHRR is already decreasing notably before $\mathrm{OH}^{*}$ chemiluminescence is detected upstream of the natural lift-off length due to the required residence time for the fuel to ignite. The small increase in AHRR before the burn-out phase of the cases with the highest heat release rates is presumably caused by the entrainment wave, also causing subsequent combustion recession [32]. All cases show similar behavior with respect to the burn-out phase, based on AHRR and optical results. However, the $\mathrm{C} 4$ case shows a slightly stronger rate of change in the central part of both the AHRR curve and the $\mathrm{OH}^{*}$ derived contour, indicating how the high injection pressure and high oxygen concentration promote combustion.

Before analyzing numerical results of high-temperature reactions, Figure 11 provides a detailed analysis of the results computed by the $k-\varepsilon$ and $k-\omega-S S T$ models for the A205 condition. The prediction of main combustion indicators in the free jet configuration was very similar for these models (see Table 4). The top panel of Figure 11 illustrates that both turbulence models predict the same steady-state liquid penetration which is reached between 0.3 and $0.5 \mathrm{~ms}$ after the start of injection. Despite a similar behaviour in the initial transient, the maximum spray penetration reached by the $k-\omega-S S T$ model is substantially larger than the one predicted by the $k-\varepsilon$ configuration. Since the momentum introduced by the spray is the same, the initial transient is mainly affected by turbulent viscosity generated by the gas velocity field. In particular, the increased liquid penetration for the $k-\omega-S S T$ model seems to be related to a reduced relative velocity between the droplets and the gas phase, which affects the breakup rate. The consequence of this is that the vapor penetration predicted by the $k-\omega-S S T$ model remains substantially larger than the one estimated using the $k-\varepsilon$ model. This first result would suggest rejecting the $k-\omega-S S T$ model but as illustrated in the bottom panel of Figure 11, both models predict a very similar air entrainment rate $\dot{m}_{e}$, which is computed as the rate of increase of the air mass which is found in an equivalence ratio range between 0.5 and 1.5. The choice of such interval is mainly related to the fact that most of the fuel is expected to burn under such conditions. The time-evolution of $\dot{m}_{e}$ shows that evaporation from the farthest droplets in the initial transient is the main reason for the increased penetration of the $k-\omega-S S T$ model compared to the $k-\varepsilon$ model, and that combustion is not expected to be significantly affected by the turbulence model used in the free jet configuration.
FIGURE 11 Comparison between $k-\varepsilon$ and $k-\omega-S S T$ turbulence models for the A205 operating condition. The top panel shows liquid and vapor penetration, while the bottom panel illustrates the similarities in air entrainment rate. Experimental vapor penetration is shown with a gray dotted line in the top panel.

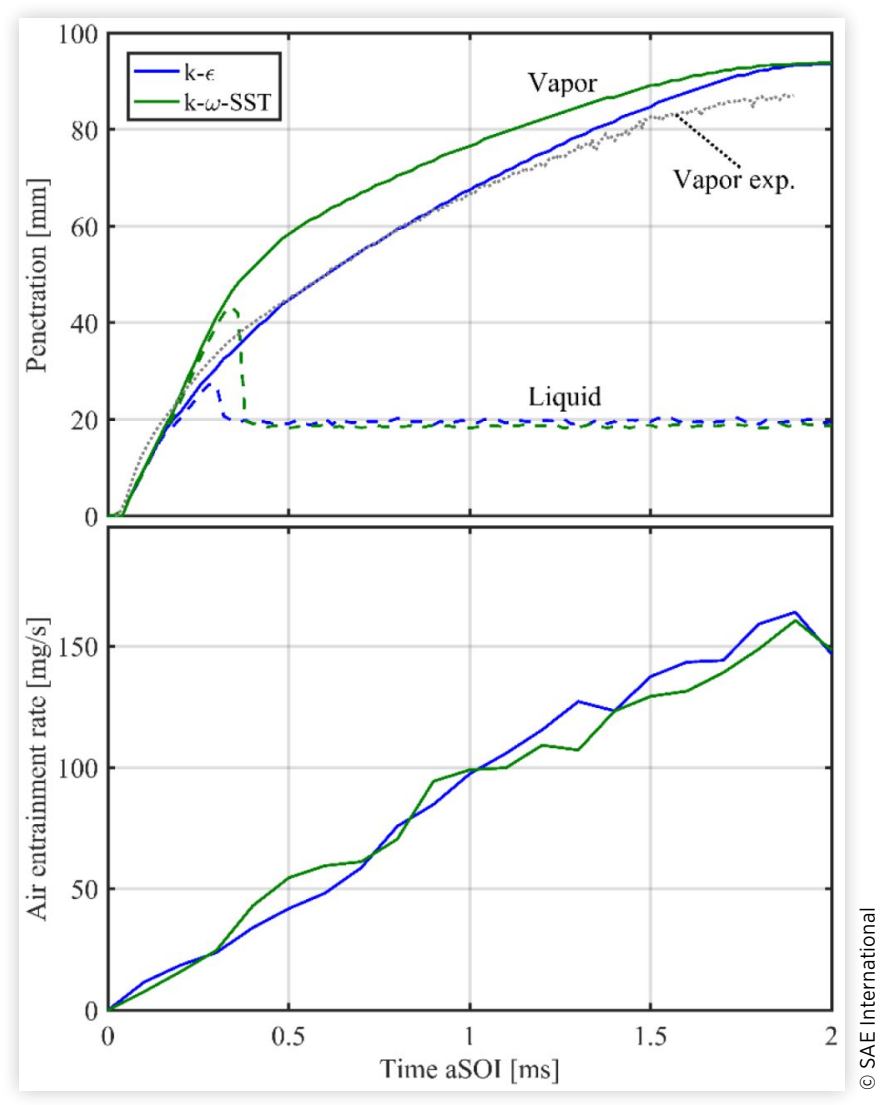

Computed AHRR traces are reported in the top panel of Figure 12. Consistently with the experimental results from Figure 10, the burning rate of the A205 case is higher than for the $\mathrm{C} 3$ case, mainly because of the increased injection pressure. Note that the experimental data, in arbitrary units, is scaled to fall within the numerical predictions. The decreased ignition delay time for the C3 condition (also refer to Table 4) is primarily caused by the increased oxygen concentration and ambient density. Numerical results for the A205 case are in rather good agreement with experimental data due to the correct description of the flame structure as shown in Figure 8. As indicated previously, liquid length values of $20 \mathrm{~mm}$ were found for the $\mathrm{C} 3$ case, meaning that the spray is surrounded by the flame in a high-temperature environment. This aspect indicates that C3 ambient conditions are strongly affecting spray evolution and fuel-air mixing. The kinetic mechanism and the combustion model were already identified as a cause for a nearzero computed lift-off length. However, AHRR results for the C3 case are still considered acceptable since the flame also stabilizes at a very short distance from the nozzle in experiments, and the general flame structure is still well captured. The suggested improvements regarding mixture fraction variance equation and TFPV table generation are expected to provide a better prediction of the FLOL for the $\mathrm{C} 3$ condition. 
FIGURE 12 Comparison between $k-\varepsilon$ and $k-\omega-S S T$ turbulence model. The top panel shows the apparent heat release rate for the $\mathrm{A} 205$ and $\mathrm{C} 3$ cases, compared to scaled experimental data from Figure 10 in grayscales. The bottom panel shows the numerical flame structure of the A205 case at $1.5 \mathrm{~ms}$ aSOI according to the color coding of Figure 8.
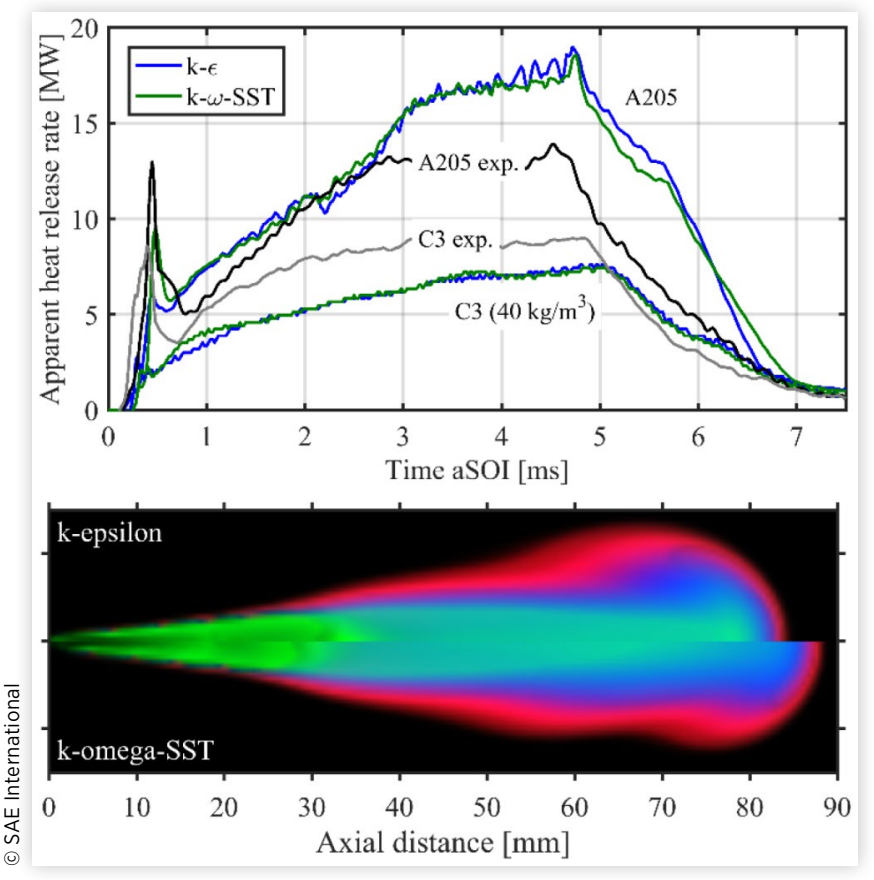

Considering the effect of the two turbulence models on computations of the AHRR, only small differences can be observed during the first millisecond of injection, and during the burn-out phase. For the sake of completeness, the quasi-steady flame structures of the A205 case obtained by the two different turbulence models are reported in the bottom panel of Figure 12. The flame stabilizes at approximately the same distance from the nozzle, and the main differences can be found at the head of the jet with a larger flame tip penetration predicted by the $k-\omega-S S T$ turbulence model.

\section{Flame-Wall Interaction}

In this section, the influence of wall interaction is studied with two different stainless-steel wall geometries and the A205 boundary conditions at $900 \mathrm{~K}, 22.8 \mathrm{~kg} / \mathrm{m}^{3}$ and an injection pressure of $150 \mathrm{MPa}$ using the $0.205-\mathrm{mm}$ orifice. For the highdensity case with an 80-MPa injection pressure, experimental flame-wall interaction data is available, but not included in this work. The first wall insert design is a simplified plane configuration, while the second one has a confined shape (cf. Figure 1). Due to the use of a $2 \mathrm{D}$ mesh in the numerical approach, the confined wall is not modeled with CFD in this work.

Although no significant influence was observed for the ratio between the bulk and the core temperature when the wall inserts were placed inside the combustion vessel, experimental AHRR results are expected to be affected. As the fuel auto-ignites during the pre-mixed burn, a strong pressure wave starts traveling radially outwards in all directions from the ignition kernel at the local speed of sound. As mentioned in the pressure analysis section, a speed-of-sound correction is applied to correct for this time-delay based on the location of the ignition location. This correction assumes a free path of travel for these pressure waves, which is not the case when a wall is placed inside the combustion vessel with the pressure transducer located in a corner opposite from the injector plane. Especially during the pre-mixed burn, which is already prone to more substantial differences between different experiments due to variation in the exact ignition location and the amount of fuel participating from case to case, experimental AHRR results are expected to be less trustworthy.

Ensemble averaged movie stills from the $\mathrm{OH}^{*}$ chemiluminescence recordings of the free jet, flat wall jet and confined wall jet are shown in Figure 13, together with the experimental AHRR. The timing after start of injection in the images from the high-speed $\mathrm{OH}^{*}$ chemiluminescence recordings were selected correspondingly to interesting phenomena in the AHRR panel of this figure. After the wall contact, the flat wall jet shows a much steeper ramp-up towards a quasi-steady AHRR, presumably due to increased mixing. Compared to

\section{FIGURE 13 Top panel; experimental $\mathrm{OH}^{*}$}

chemiluminescence results for a flat wall and a confined wall design at three different timings aSOI. The bottom panel shows the apparent heat release rates for all A205 cases. See text for more details.

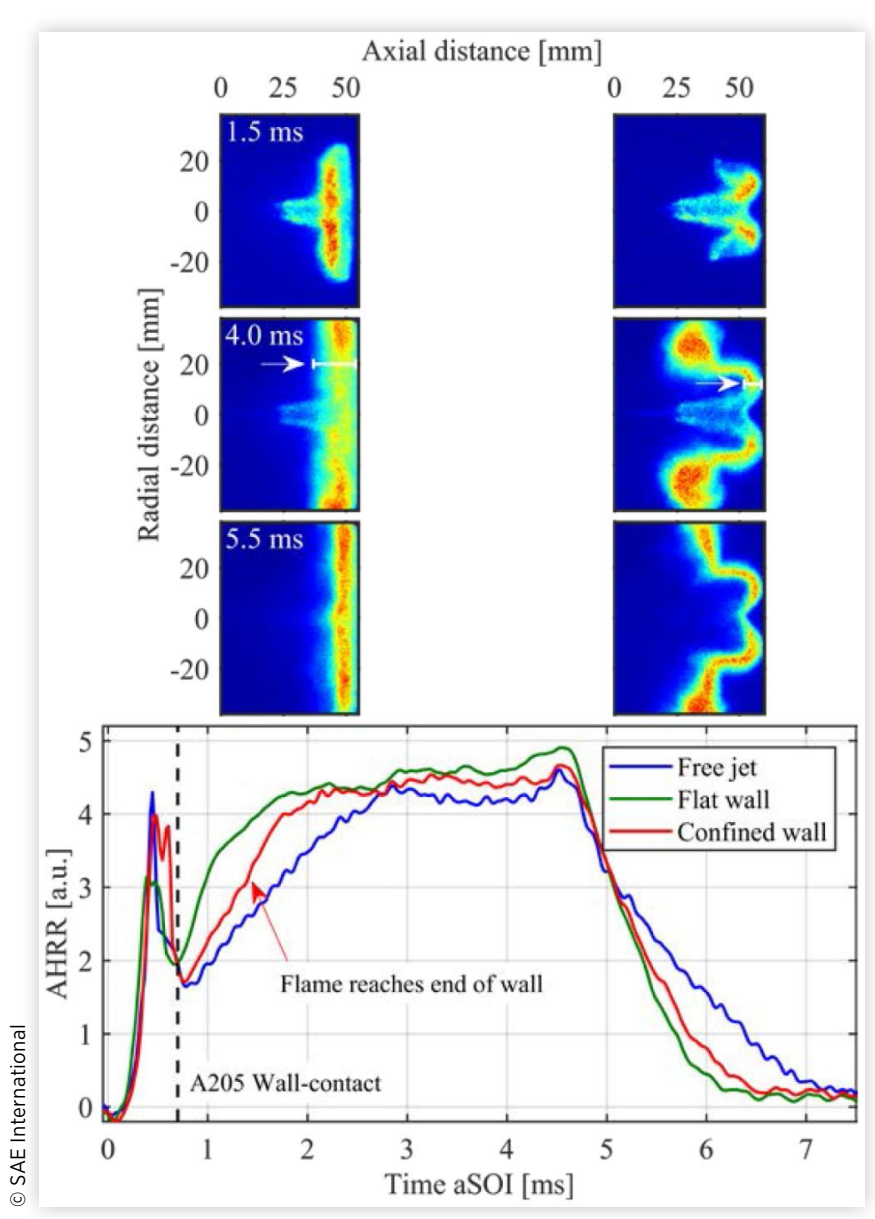


the two other cases this results in a significantly higher AHRR value at $1.5 \mathrm{~ms}$ aSOI. The confined wall increases the ramp-up compared to the free jet, but approximately half as efficient as the flat wall case. Irrespective of the signal origin, the $\mathrm{OH}^{*}$ chemiluminescence movies show a relatively larger flame area for the plane wall configuration at this time, indicating that air entrainment might be decreased for the confined wall case. Note, however, that the flame thickness of the flat wall jet near to the impingement area may be affected by the line-of-sight integration. Nevertheless, this effect is expected to be small based on the even distribution of intensity along the wall. After forcing the spray to spread out, the confined wall jet reaches the end of the wall structure around $1.5 \mathrm{~ms}$. As it detaches from the wall, it is expected to be capable of entraining more air again, which might explain the subtle increase of the slope at that point, indicated by the red arrow. There is no clear indication why the flat plane wall AHRR slope decreases around $1 \mathrm{~ms}$, but for both wall cases, the quasisteady state is reached about $1 \mathrm{~ms}$ sooner compared to the free jet.

In the quasi-steady phase at $4 \mathrm{~ms}$ aSOI, all AHRR curves are relatively close to one another. A small increase in AHRR is observed when going from a free jet to a confined jet, to the flat wall configuration, similar to the trends at $1.5 \mathrm{~ms}$ aSOI. In the $\mathrm{OH}^{*}$ panels at $4 \mathrm{~ms}$ aSOI, the observed flame thickness at the wall is quite different between the two configurations, indicated by the white brackets and white arrows in the experimental panels. Due to the more gradual spreading-out of the jet by the confined wall and the reduced line-of-sight effect, a thickness more similar to a segment of the free jet is observed. This shows how the spray is mainly forced to the top and the bottom of the wall, rather than perpendicular along the lineof-sight of the camera. At the location where the flame detaches from the wall, a spray head similar to a free jet has developed. The flat wall configuration now shows more intense regions at the furthest radial positions, confirming how the head of the jet increases the apparent flame thickness at the wall. Comparing the lift-off length values during the experiments, both wall jets do not show any sign of interaction that decreases the FLOL, as it has been observed for jet-jet interactions [65]. This confirms that the confined wall primarily represents the influence that the piston bowl-rim would have while neglecting neighboring sprays.

All sprays initially behave quite similar shortly after the end of injection, owing to the time it takes for the end-ofinjection transient (or entrainment wave [32]) to reach the location of the wall. Around $5 \mathrm{~ms}$ aSOI, the burn-out of the free jet starts to deviate from the wall jet cases, that continue to show a linear ramp-down. Around $5.5 \mathrm{~ms}$, the flat wall is slightly further along in the burn-out process, which can be related either to the higher maximum AHRR, or a still improved mixing. The flame thickness based on $\mathrm{OH}^{*}$ chemiluminescence observed in the flat wall configuration at this time is expected to be similar to the thickness found without the wall vortex in the quasi-steady state. Obviously, the lift-off location has moved downstream and has reached the wall surface by now. In the confined configuration, the most significant changes are again found in the former lift-off region and the most downstream region, where the vortex has now disappeared. Note how, in this case, the flame thickness along the curvature of the wall is quite similar still to the quasi-steady image at $4 \mathrm{~ms}$ as well. When compared to the flat wall, the thickness is still reduced. As mentioned before, this might be caused by the more gradual guidance of the spray along the confined shape, possibly not achieving a similar amount of entrainment.

Overall, the experimental results from the wall study show how the improved mixing reported by Bruneaux [21], potentially increased the heat released in between the moment of contact and the point in time where the spray reaches a quasi-steady AHRR. At the quasi-steady state, a small but consistent, increase in AHRR can still be observed. The burn-out phase after the end of injection is improved upon as well, decreasing the total burn duration. To gain more insight into the causes of the increased AHRR, both air entrainment rate and mixing where studied by numerical simulations.

Identification of the best setup in terms of mesh and turbulence model was the first task of CFD simulations. Here, only A205 results are shown since the C 3 case results show similar trends. First, effects of the turbulence model on the vapor penetration are illustrated in the top panel of Figure 14. Due to the larger vapor penetration of the $k-\omega-S S T$ model the flame touches the wall at $0.38 \mathrm{~ms}$ aSOI, much earlier than

\section{FIGURE 14 Top: comparison between computed vapor} penetration in the free jet and flat wall configuration using the $k-\varepsilon$ and $k-\omega-S S T$ turbulence models. Bottom: evolution of the air entrainment rate for the free jet and flat wall configurations using different turbulence models and mesh configurations.

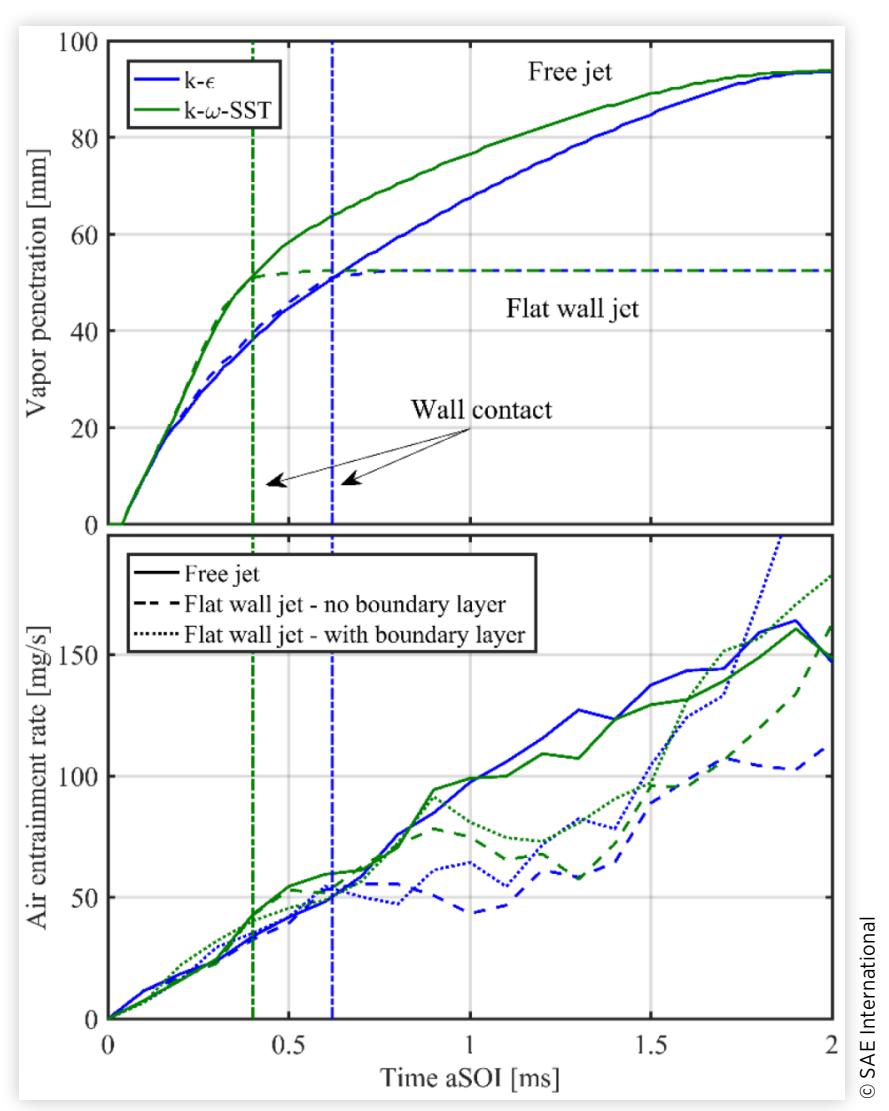


the $k-\varepsilon$ model and experimental results (around $0.65 \mathrm{~ms}$ ). The lower panel of Figure 14 reports the air entrainment rate for different simulation setups which were analyzed to understand how turbulence model, jet-wall interaction, and mesh structure affect the results. No significant differences between the free jet and flat wall cases are found until $0.6 \mathrm{~ms}$ aSOI, consistent with the experimental findings of Bruneaux [21]. This supports the finding that despite differences in penetration, and even a shorter time for wall contact, the behavior of the $k-\omega-S S T$ configuration is not significantly different from the $k-\varepsilon$ model, and again. After $0.6 \mathrm{~ms}$, it is possible to see how turbulence models and mesh structure affect the air entrainment rate for the flat wall configuration. For both the $k-\varepsilon$ and the $k-\omega-S S T$ model, mesh refinement at the wall ensures a non-dimensional wall distance value $\left(y^{+}\right)$of between 5 and 50, producing a higher air-entrainment rate. There is a slight increase in $\dot{m}_{e}$ for the refined mesh cases in the 0.6-1.5 ms interval where the flow direction changes and a boundary layer develops near the flat wall. However, the effect of mesh structure becomes even more important when the flame detaches from the wall, after $1.5 \mathrm{~ms}$, where air entrainment is mainly affected by the gas velocity profile at the wall edge. Concerning the turbulence model effect, using the $k-\omega-S S T$ setup with a boundary layer produces an air entrainment rate very similar to the free jet configuration until $1 \mathrm{~ms}$, after which it decreases. Decrease of air entrainment rate after the wall contact is even more significant when using the $k-\varepsilon$ model. These first results show how the use of a suitable mesh resolution near the walls is important to correctly estimate the air entrainment when the flame reaches the walls. Because of the complex geometry and computational cost, most engine simulations use a coarse mesh in the near-wall region, which is expected to compromise the quality of the computed results significantly.

Numerical AHRR results are shown in Figure 15, similarly showing an increased rate for the wall interaction cases during the entire injection timing. The increased air entrainment rate of the $k-\omega-S S T$ model produces a higher AHRR compared to the $k-\varepsilon$ case, but it does not explain why combustion with the flat wall insert is faster in all cases compared to the free jet configuration, which had a higher computed air entrainment rate between 1 and $1.5 \mathrm{~ms}$ aSOI.

Because the flame stabilizes upstream of the wall, another possible explanation for the increased AHRR would be an improved mixing process, leading to faster oxidation of the partially burned products [21]. To understand this hypothesis, Figure 16 shows the distribution of the mixture fraction variance segregation factor $S_{\widetilde{Z^{\prime 2}}}$, which is the ratio between actual mixture fraction variance and the maximum ideal one according to

$$
S_{\widetilde{Z^{\prime 2}}}=\frac{\widetilde{Z^{\prime \prime 2}}}{Z(1-Z)} .
$$

$S_{\overline{Z^{1 / 2}}}$ is a good indication of the mixture inhomogeneity in any cell. On the same figures, iso-contours of stoichiometric mixture fraction $\left(Z_{s t}\right)$ are reported, corresponding to the location where maximum temperatures are expected. It is possible to see that for both turbulence models, the flat wall insert increases mixing by reducing the maximum value of
FIGURE 15 Comparison between computed AHRR profiles in the free jet and flat wall configuration using the $k-\varepsilon$ and $k-\omega-S S T$ turbulence models. The lower panel shows a more detailed plot of the AHRR in the 0-2 ms time interval. Grey lines represent scaled experimental data from Figure 13.

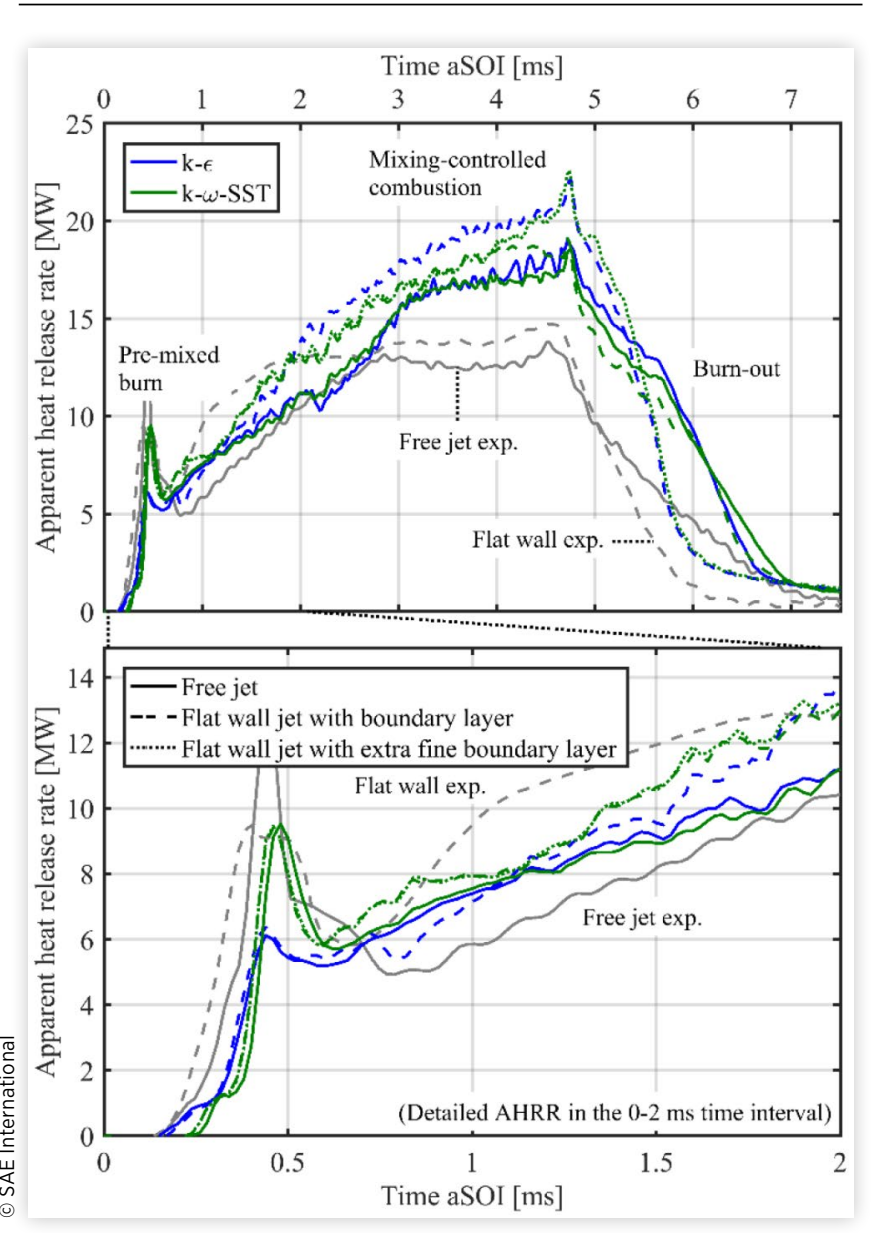

$S_{\overline{Z^{\prime \prime 2}}}$ at the tip of the flame compared to the free jet configuration. This is caused by the near-wall turbulent viscosity increase and the curvature of the jet above the wall. The isocontour of $Z_{s t}$ clearly shows that flame curvature is different between $k-\varepsilon$ and $k-\omega-S S T$ models, where the latter is capable of producing a more homogeneous mixture around $Z_{s t}$ in the vicinity of the wall. The $k-\omega-S S T$ model is characterized by more complete combustion in the head of the jet compared to the $k-\varepsilon$ model. Therefore, an increase of mixture homogeneity due to flame curvature and boundary layer development is identified as the reason for the increase of AHRR in the flat wall configuration compared to the free jet. While the $k-\omega-S S T$ model is capable of correctly reproducing the experimental trend, the $k-\varepsilon$ model shows insufficient mixing improvement which occurs much later than the time where the flame touches the wall.

The final aspect to be investigated with numerical simulations is whether an acceleration of the combustion process due to the flat wall insert corresponds also to a shorter duration of the burn-out phase after the end of injection. For both the investigated turbulence models, the flame starts to detach from the wall at approximately $1.5 \mathrm{~ms}$ aSOI and 


\section{FIGURE 16 Distribution of mixture fraction variance} segregation factor and iso-contours of stoichiometric mixture fraction at 1.5 aSOI. The top panel shows the $k-\varepsilon$ free jet versus the $k-\varepsilon$ flat wall results, while the bottom panel shows the $k-\omega-S S T$ flat wall results versus the $k-\omega-S S T$ free jet results, such that the differences at the wall are easily observed.

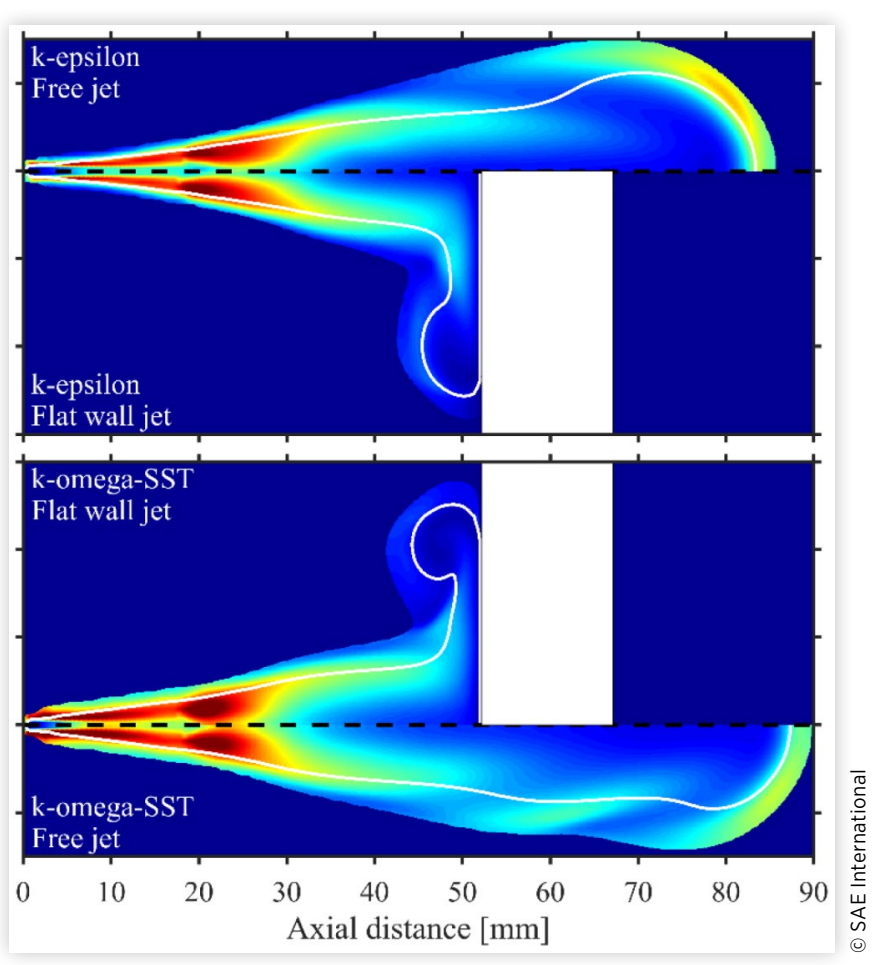

combustion is mainly affected by the flow distribution predicted at the edge of the flat wall insert. In the free jet configuration, both turbulence models predict almost a similar duration of the combustion process, finishing approximately at $7 \mathrm{~ms}$ aSOI, conform experimental data. For the flat wall configuration, experimental data from Figure 13 suggests that combustion is nearly finished at $6 \mathrm{~ms}$ aSOI. Figure 15 illustrates that the $k-\varepsilon$ model correctly reproduces this trend, although it is not capable to predict the AHRR increase when the flame touches the wall. The $k-\omega-S S T$ model unexpectedly fails the prediction of the combustion duration with the flat wall insert, despite a correct description of the faster burning rate related to flame-wall interaction. Increasing the mesh resolution in the boundary layer region of the $k-\omega-S S T$ model from 10 to 20 cells has a significant effect on the results with the flat wall, producing a correct prediction of the combustion duration. This is most likely related to a more accurate prediction of the boundary layer flow over the flat wall, affecting the velocity profile at its edge. Subsequently, this influences air entrainment when the flame detaches from the wall. For the sake of completeness, Table 5 reports the computed values of the non-dimensional wall distance value $y^{+}$over the flat wall insert. The interesting result is that, when keeping the same boundary layer mesh resolution, the different predictions of flame curvature from the two turbulence models lead to higher $y^{+}$values in the
TABLE 5 Effect of boundary layer mesh resolution and turbulence model on the computed minimum, maximum, and average non-dimensional wall distance value $\left(y^{+}\right)$for the flat wall boundary.

\begin{tabular}{|c|c|c|c|c|c|}
\hline & $\begin{array}{l}k-\varepsilon, w / o \\
\text { B.L. }\end{array}$ & $\begin{array}{l}k-\varepsilon, 10 \\
\text { B.L. }\end{array}$ & $\begin{array}{l}\text { k- } \omega \text {-SST, } \\
w / o \text { B.L. }\end{array}$ & $\begin{array}{l}\text { k- } \omega \text {-SST, } \\
10 \text { B.L. }\end{array}$ & $\begin{array}{l}\text { k- } \omega \text {-SST, } \\
20 \text { B.L. }\end{array}$ \\
\hline Min. $y^{+}$ & 25 & 2 & 26 & 0.7 & 0.1 \\
\hline Max. $y^{+}$ & 250 & 16 & 240 & 52 & 23 \\
\hline Avg. $y^{+}$ & 91 & 6 & 94 & 12 & 6 \\
\hline
\end{tabular}

$k-\omega-S S T$ case. An increase of the number of cells in the boundary layer to 20 brings the value closer to the $y^{+}$of the $k-\varepsilon$ model and improves the prediction of the combustion duration.

\section{Summary and Conclusions}

The goal of this work was to study spray combustion processes relevant to heavy-duty Diesel engine operation, and to establish a pathway from a well-defined and well-controlled optically accessible environment to real engine simulations. Combustion parameters and flame structures were investigated for heavy-duty spray flames with experimental and numerical tools. Jet-wall interaction was studied using both a flat wall, and a confined shape design simulating a piston bowl-rim. Experiments were conducted in a constant-volume pre-burn combustion chamber with full optical access. Wellcontrolled and well-characterized ambient and injector conditions were targeted to provide reliable data for numerical validation and comparison. Simultaneous formaldehyde PLIF and high-speed $\mathrm{OH}^{*}$ chemiluminescence imaging were used to visualize both low- and high-temperature combustion. Additional insight into high-temperature combustion was provided by heat-release analysis and a study of the origin of signal in $\mathrm{OH}^{*}$ chemiluminescence detection through optical filters. Based on the experiments and simulation utilized in this work, the following conclusions were drawn:

1. A significant portion of the intensity detected in $\mathrm{OH}^{*}$ chemiluminescence images may originate from soot incandescence, the more so when moving downstream of the lift-off location. For the cases studied in this work, $\mathrm{OH}^{*}$ chemiluminescence was not distinguishable in the downstream portion of the spray.

2. The formaldehyde distribution from the large orifice injector at ECN Spray A ambient conditions is similar to the results that were found for the smaller injector nozzle. This shows how it is likely to scale with the orifice diameter, similar to the lift-off length scaling law. Furthermore, it was shown how perhaps most of the $\mathrm{CH}_{2} \mathrm{O}$ signal will be obscured by $\mathrm{PAH}$ and soot luminosity during the quasi-steady state for the increased hole diameter, irrespective of the ambient conditions used in this work.

3. Fluorescence recorded at the high-density conditions with an increased oxygen percentage most likely 
contains significant contributions by PAHs, even at the early stages shortly after ignition. Based on the analysis and comparison with numerical simulations, the PAH structures seem to encompass a large part of the formaldehyde distributions.

4. From the preliminary wall experiments in this study, significant influences on AHRR were identified. All the wall jets studied in this work increase the AHRR, indicating an overall increase of mixing.

Experimental data made available in the context of this investigation allowed to identify a suitable methodology for the simulation of the combustion process in Heavy-Duty engines, including the flame-wall interaction process. The following conclusions can be drawn from CFD simulations:

1. The TFPV combustion model based on the tabulation of unsteady diffusion flame is capable of correctly predicting auto-ignition, flame stabilization and chemical species distributions. The accuracy of TFPV is similar to models based on direct integration of detailed kinetics, but the computational cost is significantly reduced.

2. The two tested turbulence models, $k-\varepsilon$ and $k-\omega-S S T$, produce very similar results in terms of combustion indicators and flame structure on the free jet configuration despite their differences when compared considering only liquid and vapor penetration. Such evaluation appears too restrictive and the use of additional metrics based on the air entrainment rate is suggested to better investigate how turbulence models influences fuel-air mixing and combustion.

3. Simulating combustion behavior in presence of jetwall interaction is very complex and involves different features related to boundary layer development and flow curvature. Within this context, the correct choice of turbulence model and near wall mesh resolution is of great importance for a successful simulation.

The combined numerical and experimental analysis furthermore identifies that the increase of mixture homogeneity due to the flame curvature and boundary layer development is most likely the reason for the increase of AHRR during injection in presence of flame-wall interaction.

\section{Recommendations}

Particularly for the study of formaldehyde with large orifice injectors and flame-wall interaction, a number of recommendations can be derived from this work for future studies.

Due to the increased contribution of PAH and soot incandescence with overlapping axial positions in formaldehyde PLIF experiments, a different excitation or detection scheme is proposed for large orifice injectors. Either detection with a multi-band filter that allows off-band imaging by angletuning, or an on- and off-resonant excitation approach are recommended for this purpose $[\underline{35}, \underline{66}]$.
Given the ambiguities in the few flame-wall interaction studies performed up until now, the influence of wall position and injection parameters should be studied in more detail. Performing more experiments and developing models where these parameters are varied with consistent results can establish guidelines for future combustion engines. When comparing a planar flat wall to the confined configuration as presented here, the furthest wall position should be studied as well to ensure that the most significant difference is due to the designed shape, rather than a small change in position. To further reduce uncertainties in experimental AHRR signal, it is recommended to place a pressure sensor on the injector side of the wall.

The influence of the specific wall design should be taken into account and studied using a more fundamental approach. Given that the wall design can have a significant influence on the heat release and burn duration, it provides another variable that can be utilized to optimize internal combustion engines.

For future experiments, more effort will be put into temperature measurements to resolve either gas temperatures in the boundary layer of the wall, or heat-flux through the wall. In combination with heat-flux measurements, extension to an investigation with so called "temperature swing heat insulation" on the inserts could provide more insight into the fundamental processes involved for these materials [67].

Concerning CFD modeling, the presented results suggest that in presence of complex geometry features, the $k-\omega-S S T$ model should be preferred over the standard $k-\varepsilon$ approach. The reason for this is not only a correct prediction of autoignition and lift-off but to include important features of heat release rate related to the interaction between the flow and the geometry. For a better description of the flame structure at high-density conditions, more work might be required to improve the kinetic mechanism.

\section{References}

1. Westlye, F.R., Battistoni, M., Skeen, S.A., Manin, J. et al., "Penetration and combustion characterization of cavitating and non-cavitating fuel injectors under diesel engine conditions," SAE Technical Paper 2016-01-0860, 2016, doi:10.4271/2016-01-0860.

2. Dahms, R.N., Paczko, G.A., Skeen, S.A., and Pickett, L.M., "Understanding the Ignition Mechanism of High-Pressure Spray Flames," Proc. Combust. Inst. 36(2):2615-2623, 2017, doi:10.1016/j.proci.2016.08.023.

3. Hessel, R., Yue, Z., Reitz, R., Musculus, M. et al., "Guidelines for Interpreting Soot Luminosity Imaging," SAE Int. J. Engines 10(3):1174-1192, 2017, doi:10.4271/2017-01-0716.

4. Maes, N., Dam, N., Somers, B., Lucchini, T. et al., "Experimental and Numerical Analyses of Liquid and Spray Penetration under Heavy-Duty Diesel Engine Conditions," SAE Int. J. Fuels Lubr. 9(1):108-124, 2016, doi:10.4271/201601-0861.

5. Payri, R., Viera, J.P., Pei, Y., and Som, S., "Experimental and Numerical Study of Lift-off Length and Ignition Delay of a Two-Component Diesel Surrogate," Fuel 158:957-967, 2015, doi:10.1016/j.fuel.2014.11.072. 
6. Anselmi, P., Kashdan, J., Bression, G., Ferrero-Lesur, E. et al., "Improving Emissions, Noise and Fuel Economy TradeOff by using Multiple Injection Strategies in Diesel Low Temperature Combustion (LTC) Mode," SAE Technical Paper 2010-01-2162, 2010, doi:10.4271/2010-01-2162.

7. Bolla, M., Farrace, D., Wright, Y.M., Boulouchos, K. et al., "Influence of Turbulence-Chemistry Interaction for N-Heptane Spray Combustion under Diesel Engine Conditions with Emphasis on Soot Formation and Oxidation," Combust. Theory Model. 18(2):330-360, 2014, doi:10.1080/13647830.2014.898795.

8. Kundu, P., Pei, Y., Wang, M., Mandhapti, R. et al., "Evaluation of Turbulence-Chemistry Interaction under Diesel Engine Conditions with Multi-Flamelet RIF Model," At. Sprays 24(9):779-800, 2014, doi:10.1615/ AtomizSpr.2014010506.

9. Wehrfritz, A., Kaario, O., Vuorinen, V., and Somers, B., "Large Eddy Simulation of N-Dodecane Spray Flames Using Flamelet Generated Manifolds," Combust. Flame 167:113131, 2016, doi:10.1016/j.combustflame.2016.02.019.

10. Chishty, M.A., Bolla, M., Hawkes, E., Pei, Y. et al., "Assessing the Importance of Radiative Heat Transfer for ECN Spray A Using the Transported PDF Method," SAE Int. J. Fuels Lubr. 9(1):100-107, 2016, doi:10.4271/2016-01-0857.

11. Akkurt, B., Akargun, H.Y., Somers, L.M.T., Deen, N.G. et al., "An Insight on the Spray-A Combustion Characteristics by Means of RANS and LES Simulations Using Flamelet-Based Combustion Models," SAE Technical Paper 2017-01-0577, 2017, doi:10.4271/2017-01-0577.

12. Lucchini, T., Della Torre, A., D’Errico, G., Onorati, A. et al., "A Comprehensive Methodology for Computational Fluid Dynamics Combustion Modeling of Industrial Diesel Engines," Int. J. Engine Res. 18(1-2):26-38, 2017, doi: $10.1177 / 1468087416679570$.

13. Engine Combustion Network Website, https://ecn.sandia. gov.

14. Colban, W.F., Kim, D., Miles, P.C., Oh, S. et al., "A Detailed Comparison of Emissions and Combustion Performance between Optical and Metal Single-Cylinder Diesel Engines at Low Temperature Combustion Conditions," SAE Int. J. Fuels Lubr. 1(1):505-519, 2008, doi:10.4271/2008-01$\underline{1066}$.

15. Baert, R.S.G., Frijters, P.J.M., Somers, B., Luijten, C.C.M. et al., "Design and Operation of a High Pressure, High Temperature Cell for HD Diesel Spray Diagnostics: Guidelines and Results," SAE Technical Paper 2009-01-0649, 2009, doi:10.4271/2009-01-0649.

16. Siebers, D.L., "Ignition Delay Characteristics of Alternative Diesel Fuels: Implications on Cetane Number," SAE Technical Paper $\underline{852102}$, 1985, doi:10.4271/852102.

17. Pickett, L.M., Genzale, C.L., Bruneaux, G., Malbec, L.-M. et al., "Comparison of Diesel Spray Combustion in Different High-Temperature, High-Pressure Facilities," SAE Int. J. Engines 3(2):156-181, 2010, doi:10.4271/2010-01-2106.

18. Meijer, M., Somers, B., Johnson, J., Naber, J. et al., "Engine Combustion Network (ECN): Characterization and Comparison of Boundary Conditions for Different Combustion Vessels," At. Sprays 22(9):777-806, 2012, doi:10.1615/AtomizSpr.2012006083.
19. Dreizler, A. and Böhm, B., "Advanced Laser Diagnostics for an Improved Understanding of Premixed Flame-Wall Interactions," Proc. Combust. Inst. 35(1):37-64, 2015, doi:10.1016/j.proci.2014.08.014.

20. Meingast, U., Staudt, M., Reichelt, L., and Renz, U., "Analysis of Spray/Wall Interaction Under Diesel Engine Conditions," SAE Technical Paper 2000-01-0272, 2000, doi:10.4271/200001-0272.

21. Bruneaux, G., "Mixing Process in High Pressure Diesel Jets by Normalized Laser Induced Exciplex Fluorescence Part II: Wall Impinging Versus Free Jet," SAE Technical Paper 2005 01-2097, 2005, doi:10.4271/2005-01-2097.

22. Magnusson, A., Andersson, S., and Jedrzejowski, S., "SprayWall Interaction: Diesel Fuels Impinging on a Tempered Wall," SAE Technical Paper 2006-01-1116, 2006, doi:10.4271/2006-01-1116.

23. Ruth, D. and O'Connor, J., "Development and Verification of Reduced-Order Model for Diesel Spray Penetration and Spreading during Wall Impingement," SAE Technical Paper 2017-01-0814, 2017, doi:10.4271/2017-01-0814.

24. Pickett, L.M. and López, J.J., "Jet-Wall Interaction Effects on Diesel Combustion and Soot Formation," SAE Technical Paper 2005-01-0921, 2005, doi:10.4271/2005-01-0921.

25. Bruneaux, G., "Combustion Structure of Free and WallImpinging Diesel Jets by Simultaneous Laser-Induced Fluorescence of Formaldehyde, Poly-Aromatic Hydrocarbons, and Hydroxides," Int. J. Engine Res. 9(3):249265, 2008, doi:10.1243/14680874JER00108.

26. Gao, J., Moon, S., Zhang, Y., Nishida, K. et al., "Flame Structure of Wall-Impinging Diesel Fuel Sprays Injected by Group-Hole Nozzles," Combust. Flame 156(6):1263-1277, 2009, doi:10.1016/j.combustflame.2009.01.014.

27. Wang, X., Huang, Z., Zhang, W., Kuti, O.A. et al., "Effects of Ultra-High Injection Pressure and Micro-Hole Nozzle on Flame Structure and Soot Formation of Impinging Diesel Spray," Appl. Energy 88(5):1620-1628, 2011, doi:10.1016/j. apenergy.2010.11.035.

28. Pickett, L.M. and Siebers, D.L., "Fuel Effects on Soot Processes of Fuel Jets at DI Diesel Conditions," SAE Technical Paper 2003-01-3080, 2003, doi:10.4271/2003-01$\underline{3080}$.

29. Higgins, B. and Siebers, D.L., "Measurement of the Flame Lift-off Location on Dl Diesel Sprays Using OH Chemiluminescence," SAE Technical Paper 2001-01-0918, 2001, doi:10.4271/2001-01-0918.

30. Dec, J.E. and Espey, C., "Chemiluminescence Imaging of Autoignition in a DI Diesel Engine," SAE Technical Paper 982685, 1998, doi:10.4271/982685.

31. Najafabadi, M.I., Egelmeers, L., Somers, B., Deen, N. et al., "The Influence of Charge Stratification on the Spectral Signature of Partially Premixed Combustion in a Light-Duty Optical Engine," Appl. Phys. B Lasers Opt. 123(4):1-13, 2017, doi:10.1007/s00340-017-6688-9.

32. Musculus, M.P.B. and Kattke, K., "Entrainment Waves in Diesel Jets," SAE Int. J. Engines 2(1):1170-1193, 2009, doi:10.4271/2009-01-1355.

33. Payri, R., García, J.M., Salvador, F.J., and Gimeno, J., "Using Spray Momentum Flux Measurements to Understand the 
Influence of Diesel Nozzle Geometry on Spray Characteristics," Fuel 84(5):551-561, 2005, doi:10.1016/j. fuel.2004.10.009.

34. Maes, N., Meijer, M., Dam, N., Somers, B. et al., "Characterization of Spray A Flame Structure for Parametric Variations in ECN Constant-Volume Vessels Using Chemiluminescence and Laser-Induced Fluorescence," Combust. Flame 174:138-151, 2016, doi:10.1016/j. combustflame.2016.09.005.

35. Bakker, P.C., Maes, N., and Dam, N., "The Potential of Onand Off-Resonant Formaldehyde Imaging Combined with Bootstrapping in Diesel Sprays," Combust. Flame 182:20-27, 2017, doi:10.1016/j.combustflame.2017.03.032.

36. Maes, N., Bakker, P.C., Dam, N., and Somers, B., "Transient Flame Development in a Constant-Volume Vessel Using a Split-Scheme Injection Strategy," SAE Int. J. Fuels Lubr. 10(2):318-327, 2017, doi:10.4271/2017-01-0815.

37. Skeen, S.A., Manin, J., and Pickett, L.M., "Simultaneous Formaldehyde PLIF and High-Speed Schlieren Imaging for Ignition Visualization in High-Pressure Spray Flames," Proc. Combust. Inst. 35(3):3167-3174, 2015, doi:10.1016/j. proci.2014.06.040.

38. Heywood, J.B., Internal Combustion Engine Fundamentals (New York: McGraw-Hill Education, 1988). ISBN:978 0-07100499-2.

39. D’Errico, G., Lucchini, T., Onorati, A., and Hardy, G., "Computational Fluid Dynamics Modeling of Combustion in Heavy-Duty Diesel Engines," Int. J. Engine Res. 16(1):112124, 2015, doi:10.1177/1468087414561276.

40. Huh, K.Y., Lee, E.J., and Koo, J.Y., "Diesel Spray Atomization Model Considering Nozzle Exit Turbulence Conditions," At. Sprays 8(4):453-469, 1998, doi:10.1615/AtomizSpr.v8.i4.60.

41. Dec, J.E., "A Conceptual Model of DI Diesel Combustion Based on Laser-Sheet Imaging*," SAE Technical Paper 970873, 1997, doi:10.4271/970873.

42. Pickett, L.M. and Siebers, D.L., "Soot in Diesel Fuel Jets: Effects of Ambient Temperature, Ambient Density, and Injection Pressure," Combust. Flame 138(1-2):114-135, 2004, doi:10.1016/j.combustflame.2004.04.006.

43. Lucchini, T., D’Errico, G., Contino, F., and Jangi, M., "Towards the Use of Eulerian Field PDF Methods for Combustion Modeling in IC Engines," SAE Int. J. Engines 7(1):286-296, 2014, doi:10.4271/2014-01-1144.

44. Lehtiniemi, H., Zhang, Y., Rawat, R., and Mauss, F., "Efficient 3-D CFD Combustion Modeling with Transient Flamelet Models," SAE Technical Paper 2008-01-0957, 2008, doi:https://doi.org/10.4271/2008-01-0957.

45. Lucchini, T., D’Errico, G., Onorati, A., Frassoldati, A. et al., "Modeling Non-Premixed Combustion Using Tabulated Kinetics and Different Fame Structure Assumptions," SAE Int. J. Engines 10(2):593-607, 2017, doi:10.4271/2017-01-0556.

46. Barths, H., Hasse, C., and Peters, N., "Computational Fluid Dynamics Modelling of Non-Premixed Combustion in Direct Injection Diesel Engines," Int. J. Engine Res. 1(3):249267, 2000, doi:10.1243/1468087001545164.

47. Naud, B., Novella, R., Pastor, J.M., and Winklinger, J.F., "RANS Modelling of a Lifted H2/N2 flame Using an Unsteady Flamelet Progress Variable Approach with
Presumed PDF," Combust. Flame 162(4):893-906, 2015, doi:10.1016/j.combustflame.2014.09.014.

48. Michel, J.B., Colin, O., Angelberger, C., and Veynante, D., "Using the Tabulated Diffusion Flamelet Model ADF-PCM to Simulate a Lifted Methane-Air Jet Flame," Combust. Flame 156(7):1318-1331, 2009, doi:10.1016/j. combustflame.2008.12.012.

49. Frassoldati, A., D’Errico, G., Lucchini, T., Stagni, A. et al., "Reduced Kinetic Mechanisms of Diesel Fuel Surrogate for Engine CFD Simulations," Combust. Flame 162(10):39914007, 2015, doi:10.1016/j.combustflame.2015.07.039.

50. Maghbouli, A., Lucchini, T., D'Errico, G., and Onorati, A., "Effects of Grid Alignment on Modeling the Spray and Mixing Process in Direct Injection Diesel Engines under Non-reacting Operating Conditions," Appl. Therm. Eng. 91:901-912, 2015, doi:10.1016/j.applthermaleng. 2015.07.051.

51. Launder, B.E. and Spalding, D.B., Lectures in Mathematical Models of Turbulence (New York: Academic Press London, 1972).

52. Lucchini, T., Della Torre, A., Onorati, A., Maes, N. et al., "A Comprehensive Methodology for CFD Combustion Modeling of Industrial Diesel Engines," Int. J. Engine Res. 18(1-2):1-23, 2016.

53. Menter, F.R., "Two-Equation Eddy-Viscosity Turbulence Models for Engineering Applications," AIAA J. 32(8):15981605, 1994, doi: $10.2514 / 3.12149$.

54. Wilcox, D.C., Turbulence Modeling for CFD Third Edition (La Canada, CA: DCW Industries, 1993).

55. Luque, J. and Crosley, D.R., "LIFBASE: Database and Spectral Simulation Program (Version 2.1)," SRI International Report 99-009, 1999.

56. Siebers, D.L. and Higgins, B., "Flame Lift-Off on DirectInjection Diesel Sprays Under Quiescent Conditions," SAE Technical Paper 2001-01-0530, 2001, doi:10.4271/2001-01$\underline{0530}$.

57. Cenker, E., Bruneaux, G., Pickett, L.M., and Schulz, C., "Study of Soot Formation and Oxidation in the Engine Combustion Network (ECN), Spray A: Effects of Ambient Temperature and Oxygen Concentration," SAE Int. J. Engines 6:352-365, 2013, doi:10.4271/2013-01-0901.

58. Idicheria, C.A. and Pickett, L.M., "Formaldehyde Visualization Near Lift-off Location in a Diesel Jet," SAE Technical Paper 2006-01-3434, 2006, doi:10.4271/2006-01$\underline{3434}$.

59. García-oliver, J.M., Malbec, L., Baya, H., and Bruneaux, G., "A Study on the Interaction between Local Flow and Flame Structure for Mixing-Controlled Diesel Sprays," Combust. Flame 179:157-171, 2017, doi:10.1016/j. combustflame.2017.01.023.

60. Davidovic, M., Falkenstein, T., Bode, M., Cai, L. et al., "LES of n-Dodecane Spray Combustion Using a Multiple Representative Interactive Flamelets Model," Oil Gas Sci. Technol. 72(5), 2017, doi:10.2516/ogst/2017019.

61. Pickett, L.M., Siebers, D.L., and Idicheria, C.A., "Relationship Between Ignition Processes and the Lift-Off Length of Diesel Fuel Jets," SAE Technical Paper 2005-013843, 2005, doi:10.4271/2005-01-3843. 
62. Payri, R., García-Oliver, J.M., Xuan, T., and Bardi, M., “A Study on Diesel Spray Tip Penetration and Radial Expansion under Reacting Conditions," Appl. Therm. Eng. 90:619-629, 2015, doi:10.1016/j.applthermaleng.2015.07.042.

63. Olguin, H. and Gutheil, E., "Influence of Evaporation on Spray Flamelet Structures," Combust. Flame 161(4):987-996, 2014, doi:10.1016/j.combustflame.2013.10.010.

64. Pickett, L.M., Manin, J., Genzale, C.L., Siebers, D.L. et al., "Relationship Between Diesel Fuel Spray Vapor Penetration/ Dispersion and Local Fuel Mixture Fraction," SAE Int. J. Engines 4(1):764-799, 2011, doi:10.4271/2011-01-0686.

65. Lequien, G., Li, Z., Andersson, O., and Richter, M., "Lift-Off Length in an Optical Heavy-Duty Diesel Engine: Effects of Swirl and Jet-Jet Interactions," SAE Int. J. Engines 8(5):21882198, 2015, doi:10.4271/2015-24-2442.

66. Thering, H., Beckmann, L., Jördens, C., Röder, M. et al., "Formaldehyde Laser-Induced Fluorescence Imaging with a Multi-Band Transmission Filter," Opt. Lett. 39(7):1873-1876, 2014, doi:10.1364/OL.39.001873.

67. Kosaka, H., Wakisaka, Y., Nomura, Y., Hotta, Y. et al., "Concept of 'Temperature Swing Heat Insulation' in Combustion Chamber Walls, and Appropriate ThermoPhysical Properties for Heat Insulation Coat," SAE Int. J. Engines 6(1):142-149, 2013, doi:10.4271/2013-01-0274.

\section{Contact Information}

\section{Noud Maes}

Department of Mechanical Engineering

Eindhoven University of Technology

P.O. Box 513

$5600 \mathrm{MB}$, Eindhoven, the Netherlands

n.c.j.maes@tue.nl

\section{Prof. Tommaso Lucchini}

Department of Energy, Politecnico di Milano

Via Lambruschini, 4

20156 Milano, Italy

tommaso.lucchini@polimi.it

\section{Acknowledgments}

Experiments were conducted at the Multiphase and Reactive Flows facility of the Eindhoven University of Technology. Financial support for this work was provided by FPT-Motorenforschung AG. Michael Harter, Hans van Griensven and Theo de Groot are gratefully acknowledged for their excellent technical support. Likewise, Lyle Pickett is gratefully acknowledged for the fruitful discussions on the signal analysis of $\mathrm{OH}^{*}$ chemiluminescence. 